\title{
Pathogenic mutations in the chromokinesin KIF22 disrupt anaphase chromosome segregation
}

\author{
Alex F. Thompson ${ }^{1}$, Patrick R. Blackburn ${ }^{2,3}$, Dusica Babovic-Vuksanovic ${ }^{2,4}$, Jane B. Lian ${ }^{5}$, Eric \\ W. Klee ${ }^{6}$, Jason K. Stumpff ${ }^{*}$ \\ ${ }^{1}$ Molecular Physiology and Biophysics, University of Vermont, Burlington, VT \\ ${ }^{2}$ Laboratory Medicine and Pathology, Mayo Clinic, Rochester, MN \\ ${ }^{3}$ Pathology, St. Jude Children's Research Hospital, Memphis, TN \\ ${ }^{4}$ Clinical Genomics, Mayo Clinic, Rochester, MN \\ ${ }^{5}$ Biochemistry, University of Vermont, Burlington, VT \\ ${ }^{6}$ Biomedical Informatics, Mayo Clinic, Rochester, MN \\ *Corresponding author, jason.stumpff@uvm.edu
}

Running Title: KIF22 mutations disrupt chromosome segregation

\section{ABSTRACT}

The chromokinesin KIF22 generates pushing forces that contribute to mitotic chromosome congression and alignment. Mutations in the motor domain of KIF22 have been identified in patients with abnormal skeletal development, and we report the identification of a patient with a novel mutation in the KIF22 tail. We assessed whether pathogenic mutations affect the function of KIF22 in mitosis and demonstrate that mutations do not result in a loss of KIF22 function. Instead, mutations disrupted chromosome segregation in anaphase, resulting in reduced proliferation, abnormal daughter cell nuclear morphology and, in a subset of cells, cytokinesis failure. This phenotype could be explained by a failure of KIF22 to inactivate in anaphase. Consistent with this model, constitutive activation of the motor phenocopied the effects of pathogenic mutations. These findings offer insight into the mechanism by which mutations in KIF22 may affect human development, the consequences of imbalance between polar ejection forces and antiparallel microtubule sliding in anaphase, and potential mechanisms of KIF22 regulation.

\section{INTRODUCTION}

Mitosis requires mechanisms that mechanically control chromosome movements to ensure equal segregation of chromosomes to daughter cells. Forces that move mitotic chromosomes are generated by microtubule dynamics within the mitotic spindle and by molecular motor proteins. The chromokinesin KIF22 (or Kid, kinesin-like DNA-binding protein) is a plus-end directed member of the kinesin-10 family (Yajima et al. 2003). KIF22 and its orthologs, including 
Murray 2000; Takagi et al. 2013; Antonio et al. 2000), generate forces that move chromosomes away from the spindle poles. Structurally, KIF22 contains a conserved kinesin motor domain responsible for ATP hydrolysis and microtubule binding (Tokai et al. 1996; Yajima et al. 2003), a second microtubule binding domain in the tail (Shiroguchi et al. 2003), a predicted coiled-coil domain (Shiroguchi et al. 2003), and a C-terminal DNA binding domain which includes a helixhairpin-helix motif (Tokai et al. 1996) (Figure 1A).

In interphase, KIF22 localizes to the nucleus (Tokai et al. 1996; Levesque and Compton 2001). As cells enter mitosis, chromosomes condense and KIF22 binds along chromosome arms (Tokai et al. 1996; Levesque and Compton 2001). In prometaphase, chromosomes must congress and align at the center of the spindle. The interactions of the KIF22 motor domain with spindle microtubules and the KIF22 tail domain with chromosome arms allows the motor to generate polar ejection forces (Brouhard and Hunt 2005; Bieling et al. 2010), which push the arms of chromosomes away from the spindle poles and towards the center of the spindle (Rieder et al. 1986; Rieder and Salmon 1994; Marshall et al. 2001), contributing to chromosome congression in prometaphase (Levesque and Compton 2001; Wandke et al. 2012; lemura and Tanaka 2015), as well as chromosome arm orientation (Levesque and Compton 2001; Wandke et al. 2012). In metaphase, polar ejection forces also contribute to chromosome oscillation and alignment (Funabiki and Murray 2000; Antonio et al. 2000; Levesque and Compton 2001; Levesque et al. 2003; Tokai-Nishizumi et al. 2005; Stumpff et al. 2012; Takagi et al. 2013). Purified KIF22 is monomeric (Shiroguchi et al. 2003), and the forces generated by KIF22 on chromosomes arms may represent the collective action of many monomers. In anaphase, KIF22 is inactivated to reduce polar ejection forces and allow chromosomes to segregate towards the spindle poles (Soeda et al. 2016; Su et al. 2016; Wolf et al. 2006)

The generation of polar ejection forces by KIF22 is regulated by the activity of cyclindependent kinase 1 (CDK1)/cyclin B, which is high in prometa- and metaphase, and drops sharply at the metaphase to anaphase transition when cyclin B is degraded (Morgan 1995; Hershko 1999). KIF22 is phosphorylated by CDK1/cyclin B at T463, a residue in the tail of the motor between the second microtubule binding and coiled-coil domains. Phosphorylation of T463 is required for polar ejection force generation in prometa- and metaphase, and dephosphorylation of T463 is necessary for the suspension of polar ejection forces to allow chromosome segregation in anaphase (Soeda et al. 2016). Reduced polar ejection forces in anaphase are one component of an overall shift in force balance at the metaphase to anaphase transition as microtubule dynamics and motor activities change to promote anaphase chromosome segregation rather than metaphase congression. In addition to its activity, the expression level of KIF22 is also regulated 
74 as the cell cycle progresses. Expression is highest in G2 phase and mitosis, and drops as cells 75 exit mitosis (Germani et al. 2000; Yount et al. 2015).

Mutations in KIF22 have been identified in patients with a developmental disorder, spondyloepimetaphyseal dysplasia with joint laxity, leptodactylic type (SEMDJL2, also referred to as Hall Type or lepto-SEMDJL) (Min et al. 2011; Boyden et al. 2011; Tüysüz et al. 2014). Four point mutations in two amino acids have been reported in SEMDJL2 patients (Min et al. 2011; Boyden et al. 2011; Tüysüz et al. 2014) (Figure 1A). These mutations occur in adjacent residues P148 and R149 in the $\alpha 2$ helix of the KIF22 motor domain (Figure 1B). P148 and R149 are conserved in kinesin-10 family members across species (Figure 1C) and in many human members of the kinesin superfamily (Figure 1D). However, no pathogenic mutations in the homologous proline or arginine residues have been recorded in OMIM (Online Mendelian Inheritance in Man, https://omim.org/). All identified patients are heterozygous for a single mutation in KIF22. Mutations dominantly cause SEMDJL2, and patients with both de novo and inherited mutations in KIF22 have been identified (Min et al. 2011; Boyden et al. 2011).

Although KIF22 mRNA is expressed throughout the body (Human Protein Atlas, http://www.proteinatlas.org (Uhlen et al. 2015)), the effects of these mutations are largely tissuespecific, and the development of the skeletal system is most affected in SEMDJL2 patients. A primary symptom of SEMDJL2 is short stature, resulting from shortening of both the trunk and the limbs. Additionally, patients present with joint laxity, midface hypoplasia, scoliosis, and leptodactyly, a narrowing of the fingers (Min et al. 2011; Boyden et al. 2011). In very young children, the softness of the cartilage in the larynx and trachea can cause respiratory issues (Boyden et al. 2011). Growth plate radiology demonstrated delayed maturation of the metaphyses and epiphyses in SEMDJL2 patients, and symptoms became more pronounced as patients aged (Tüysüz et al. 2014). Leptodactyly, specifically, was only observed in older (young adult) patients (Boyden et al. 2011).

Pathogenic mutations in the KIF22 motor domain were predicted to be loss of function mutations (Min et al. 2011). However, KIF22 knockout in mice did not affect skeletal development. Loss of KIF22 was lethal early in embryogenesis for approximately $50 \%$ of embryos, but mice that survived past this point developed to adulthood and demonstrated no gross abnormalities or pathologies (Ohsugi et al. 2003). As such, the cellular mechanism by which mutations in KIF22 affect development is unknown.

Here we characterize an additional patient with a mutation in KIF22 and assess the effect of previously reported and novel pathogenic mutations on the function of KIF22 in mitosis. We demonstrate that mutations are not loss of function mutations, and do not alter the localization of 
108

109

110

111

112

113

114

115

116

117

118

119

120

121

122

123

124

125

126

127

128

129

130

131

132

133

134

135

136

137

138

139

140

the motor or the generation of polar ejection forces in prometaphase. Instead, mutations disrupt anaphase chromosome segregation, consistent with continued KIF22 activation and consequent polar ejection force generation in anaphase. Defects in anaphase chromosome segregation affect daughter cell nuclear morphology and, in a subset of cells, prevent cytokinesis. These findings demonstrate that anaphase inactivation of KIF22 is critical for daughter cell fitness. As such, mitotic defects may contribute to pathogenesis in patients with KIF22 mutations. Additionally, we demonstrate that aberrant polar ejection force generation in anaphase is sufficient to affect the movements of not only the chromosomes but also the spindle poles, offering insight into the balance of forces required in anaphase for accurate chromosome segregation.

\section{RESULTS}

\section{A novel mutation in KIF22 affects development}

We report the identification and characterization of a patient with a novel mutation in KIF22 (Figure 1E). The patient is a 15-year-old male with a history of short stature, cryptorchidism and shawl scrotum, minimal scoliosis, secondary enuresis, and skin hyperpigmentation. He presented for evaluation at 9 years of age. At that time, his height was just below $3 \%$ for age, weight was at $40 \%$ for age, and BMI was $82 \%$ for age. He was noted to have relative macrocephaly, with a head circumference at $93 \%$ for age. He had a broad forehead and hypertelorism, round face, flaring of eyebrows, and ankyloglossia. He also had mild brachydactyly (Figure 1F). He had a history of short stature since infancy, but followed a trajectory close to the third percentile. Growth hormone and thyroid function were normal. Bone age showed a normal, age-appropriate bone maturation with normal epiphyseal ossification centers. However, skeletal survey at age 11 years disclosed mild scoliosis of 14 degrees, as well as mild increase of the central anteroposterior diameter of several lower thoracic vertebrae with mild "bullet-shaped" appearance, mild posterior scalloping of the lumbar vertebrae, and mild foreshortening of both 4th metacarpals (Figure 1G).

Genetic testing was performed to determine the cause of these developmental differences. Clinical whole exome sequencing revealed two variants of uncertain significance: a maternally inherited heterozygous SLC26A2 variant [NM_000112.3(SLC26A2): c.1046T>A (p.F349Y)] (SCV000782516.1) as well as a de novo heterozygous KIF22 variant [NM_007317.3(KIF22):c.1424T>G (p.V475G)] (SCV000782515.1) (Figure 1E). The SLC26A2 gene encodes the diastrophic dysplasia sulfate transporter (Rossi and Superti-Furga 2001; Haila et al. 2001). However, results of carbohydrate deficient transferrin testing were not consistent with a congenital disorder of glycosylation (transferrin tri-sialo/di-oligo ratio 0.07 ). 
The c.1424T>G, p.(V475G) KIF22 variant has not been observed previously in the

142 Genome Aggregation Database (gnomAD). This missense variant has mixed in silico predictions

143 of significance. V475G is predicted to be deleterious by Sorting Intolerant from Tolerant (SIFT)

144 (Vaser et al. 2015) (score 0.01 with scores ranging from 0 to 1 and scores below 0.05 considered

145 deleterious), benign by Polymorphism Phenotyping (PolyPhen-2) (Adzhubei et al. 2010) (score

146 0.437), deleterious by MutationTaster (Schwarz et al. 2010), which employs a Bayes classifier to

147 predict the disease potential of a variant, deleterious by Combined Annotation Dependent

148 Depletion (CADD) (Rentzsch et al. 2018) (scaled C-score 15.3800, with a score of greater than

149 or equal to 10 indicating a deleterious substitution), deleterious by Deleterious Annotation of

150 Genetic Variants Using Neural Networks (DANN) (Quang et al. 2015) (score 0.99 with scores

151 ranging from 0 to 1 and higher values indicating a variant is more likely to be deleterious), and

152 benign using Rare Exome Variant Ensemble Learner (REVEL) (Ioannidis et al. 2016) (score 0.28

153 with scores ranging from 0 to 1 and scores $>0.803$ classified as pathogenic). According to

154 American College of Medical Genetics 2015 criteria, the variant was classified as a variant of 155 uncertain significance (VUS). V475 is located in the coiled-coil domain in the tail of KIF22 (Figure 156 1A). This residue is conserved in most kinesin-10 family members across species (Figure 1C). 157 However, the tail domains of kinesin motors diverge in both structure and function, and as such 158 meaningful alignments to assess the conservation of V475 across the human kinesin superfamily 159 were not possible. 
bioRxiv preprint doi: https://doi.org/10.1101/2021.09.29.462402; this version posted November 19, 2021. The copyright holder for this preprint (which was not certified by peer review) is the author/funder, who has granted bioRxiv a license to display the preprint in perpetuity. It is made available under aCC-BY 4.0 International license.

\section{Figure 1}

A

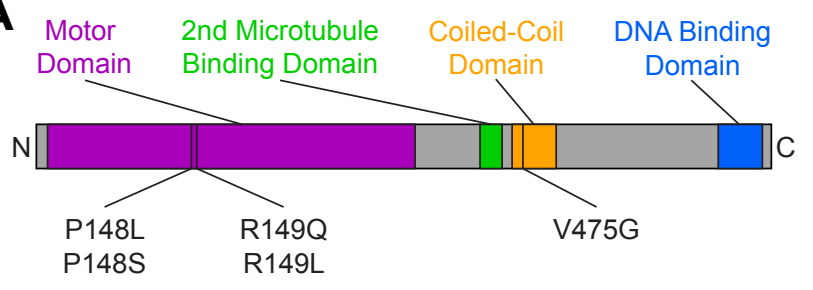

B

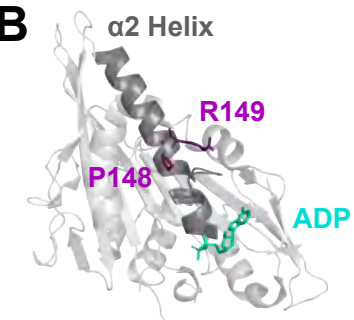

468 RMVLMKT EEKDLEI 482

463 RMVLMKT EEKNLEI 477

450 RMALLKKWEESQMEI 464

426 RLNLLKT AQSRKEI 440

463 RMVLMKT EEKDLEI 477

445 NSTLMGI EETEPK- 459
D

KIF22 141 PEOPGVIPRALMDLLOLTREE 16 KIF5A 122 PQLMGIIPRIARDIFNHIYSM 142 KIF5B 121 PEGMGIIPRIVQDIFNYIYSM 141

KIF5C 122 PQLMGIIPRIAHDIFDHIYSM 142

KIF3A 116 PELRGIIPNSFAHIFGHIAKA 136

KIF3B 112 PEKRGVIPNSFDHIFTHISRS 132

KIF3C 113 PELRGVIPNAFEHIFTHISRS 133

KIF17 107 PSQRGIIPRAFEHVFESVQCA 127

KIF1A 112 KDQQGIIPQLCEDLFSRINDT 132

KIF1B 112 ESQAGIIPQLCEELFEKINDN 132

KIF1C 112 PGQQGIVPQLCEDLFSRVSEN 132

KIF13A 116 -EQLGLIPRLCCALFKRISLE 135

KIF13B 117 -DQPGLIPRLCSGLFERTQKE 136

KIF4B 108 EPTVGIIPRVIQLLFKEIDKK 128

KIF7 114 EDEQGIVPRAMAEAFKLIDEN 135

KIF21A 108 EEELGIISRAVKHLFKSIEEK 128

KIF21B 107 EEEQGIIPRAIAHLFGGIAER 127

KIF11 128 DPLAGIIPRTLHQIFEKLTD- 147

KIF20A 176 --DGGILPRSLALIFNSLQGQ 194

KIF20B 168 --NIGILPRTLNVLFDSLOER 196

KIF23 128 --EGGLLPRCLDMIFNSIGSF 146

KIF10 101 --HLGVIPRAIHDIFQKIKKF 119

KIF18A 125 ADEPGVMYLTMLHLYKCMDEI 145

KIF18B 121 EGDPGIMYLTTVELYRRLEAR 141

KIF19 116 DQEPGIYVQTLNDLFRAIEET 136

KIF6 113 YSDRGIIPRTLSYIFEQLQKD 133

KIF9 109 YKHRGILPRALQQVFRMIEER 129

KIF12 128 PSLAGIMQRTFAWL---LDRV 145

KIF15 130 HNLRGVIPRSFEYLFSLIDRE 130
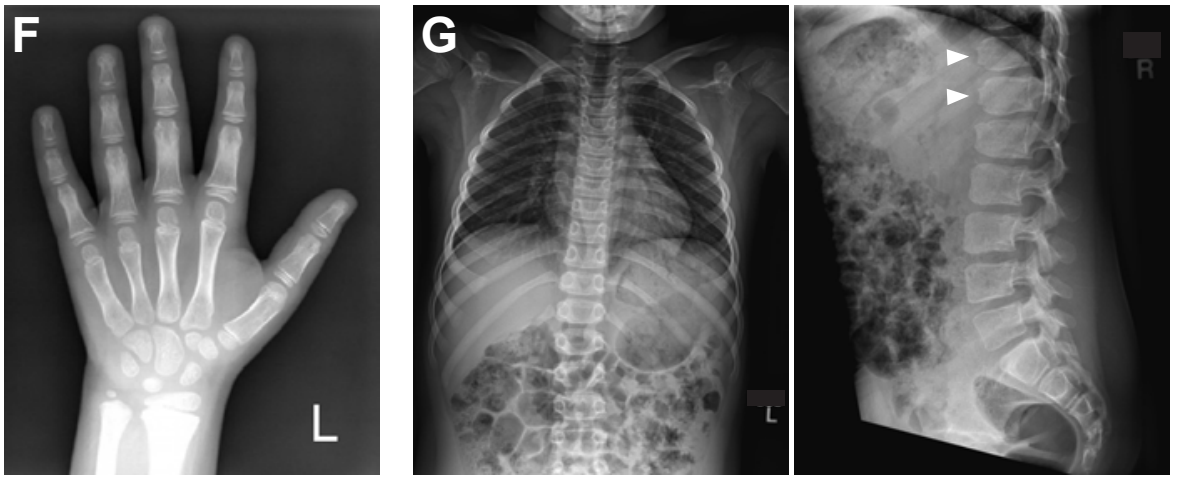


\section{Figure 1. Identification of a novel pathogenic mutation in the tail of KIF22.}

161 (A) Schematic of the domains of KIF22 with pathogenic mutations in the motor domain (magenta) 162 and coiled-coil domain (yellow) indicated. (B) Location of amino acids P148 and R149 in the 163 alpha-2 helix of the KIF22 motor domain (PDB 6NJE). (C) Alignment of amino acid sequences of 164 kinesin-10 family members to assess conservation of motor domain (P148 and R149, left) and 165 coiled-coil domain (V475G, right) residues across species. (D) Alignment of amino acid 166 sequences of human kinesin motors to assess conservation of motor domain residues across the 167 kinesin superfamily. For $C$ and D, alignments were performed using Clustal Omega. (E) Pedigree 168 identifying the de novo V475G (1424 T>G) mutation. (F) Radiograph of the patient's hand, 169 posteroanterior view. (G) Radiographs of the patient's spine. Left: anteroposterior view of the 170 chest, right: lateral view of the lumbo-sacral spine. Arrowheads indicate "bullet-shaped" vertebrae. 
bioRxiv preprint doi: https://doi.org/10.1101/2021.09.29.462402; this version posted November 19, 2021. The copyright holder for this preprint (which was not certified by peer review) is the author/funder, who has granted bioRxiv a license to display the preprint in perpetuity. It is made available under aCC-BY 4.0 International license.

\section{Supplemental Figure 1}

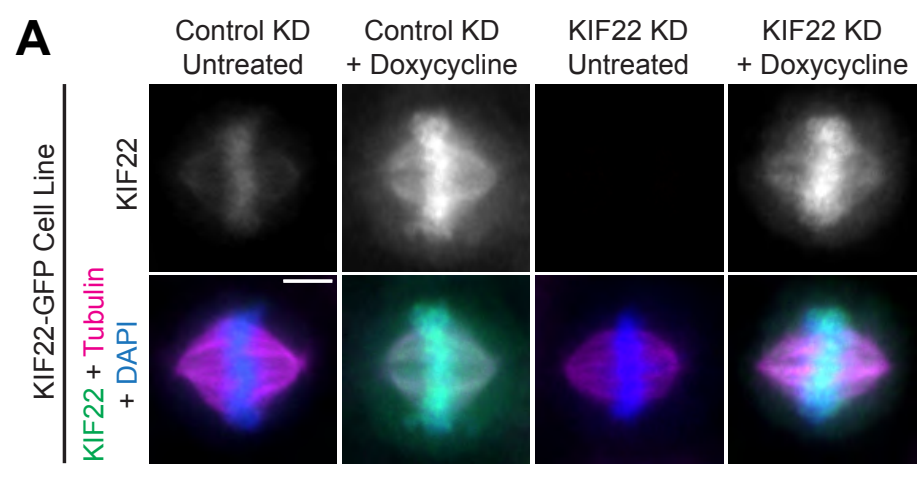

B

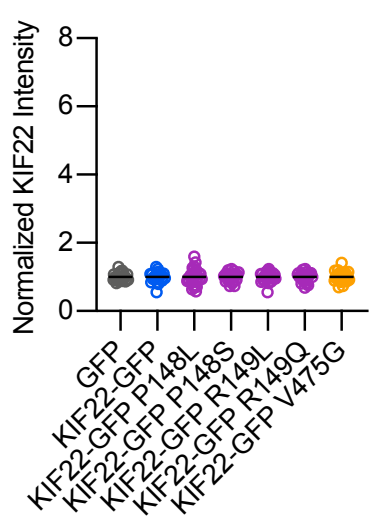

\section{$\mathbf{F}$}

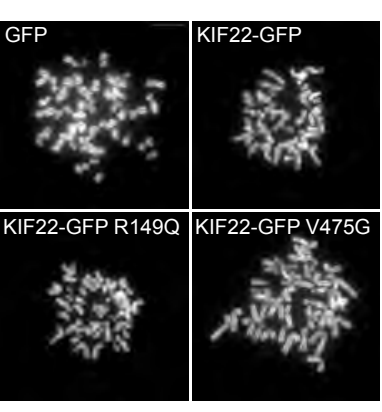

H

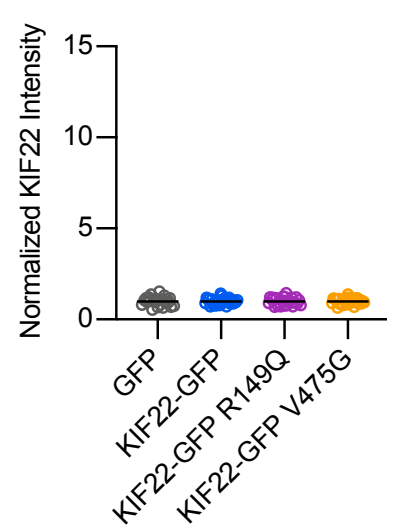

C

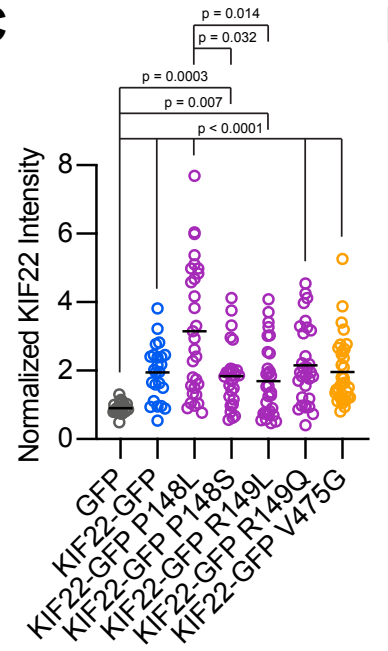

D

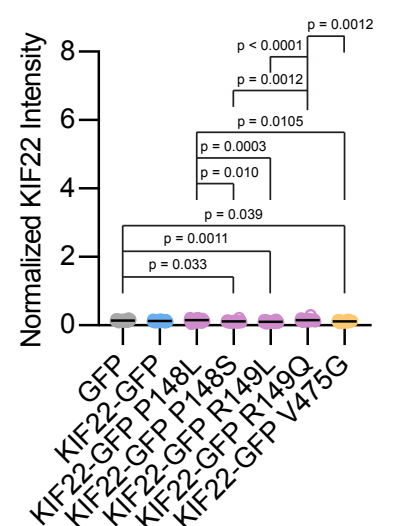

E

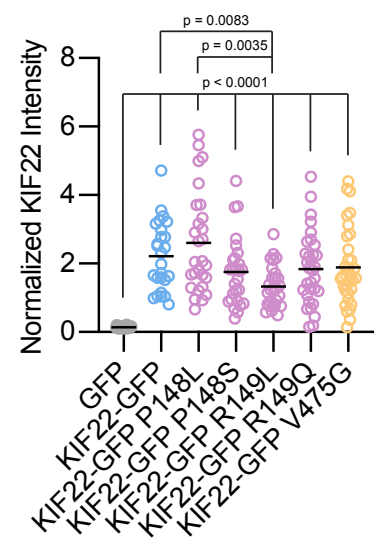

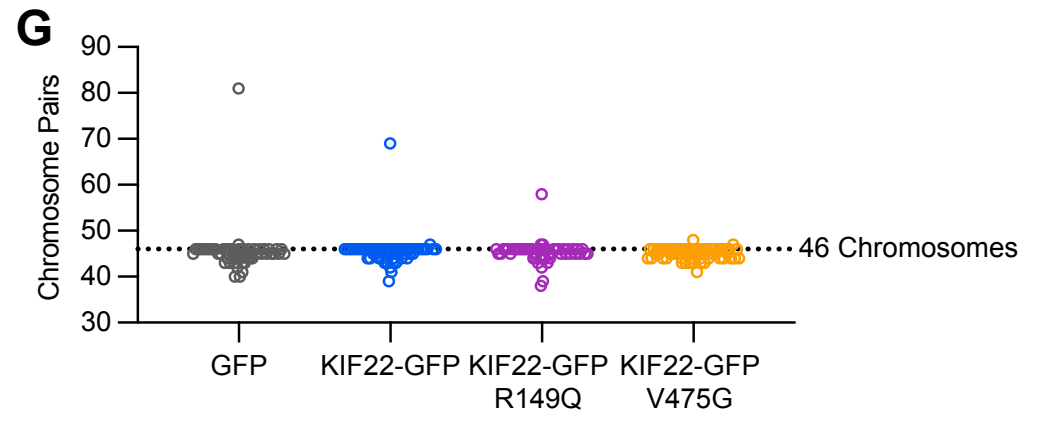
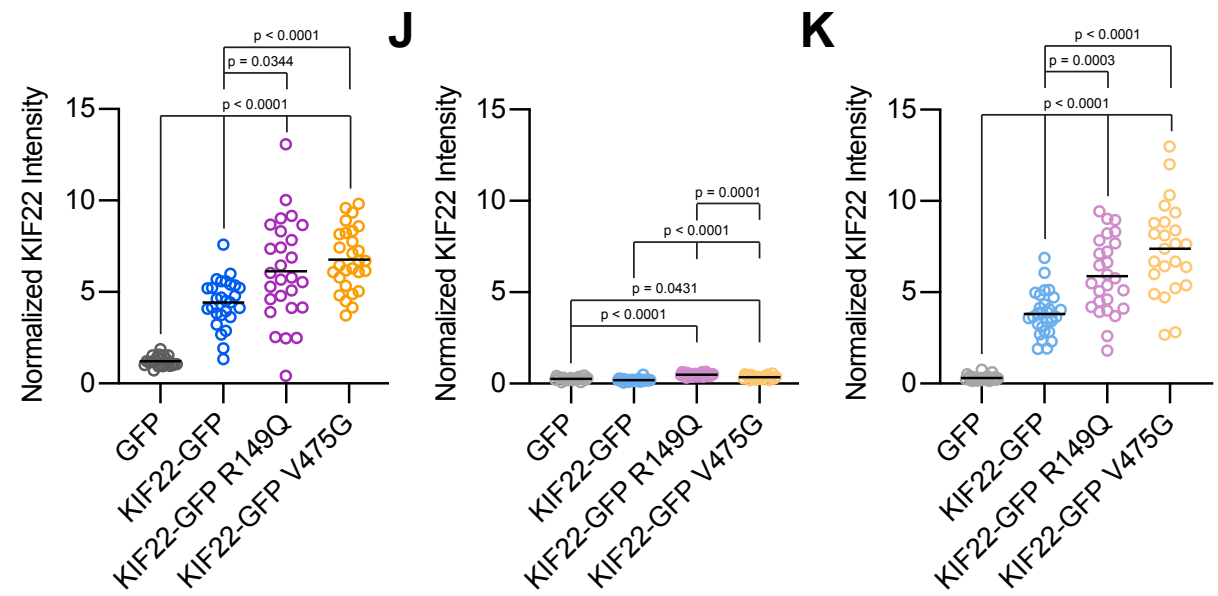
171 Supplemental Figure 1. HeLa-Kyoto and RPE-1 stable cell lines express mutant KIF22.

172 (A) Immunofluorescence images of HeLa-Kyoto cells expressing KIF22-GFP under the control of 173 a doxycycline inducible promoter. Images are maximum intensity projections in $z$ of five frames 174 at the center of the spindle. Fixed approximately 24 hours after siRNA transfection and treatment 175 with doxycycline to induce expression. Scale bar $5 \mu \mathrm{m}$. KD: knockdown. (B-E) Quantification of 176 KIF22 fluorescence intensity in untreated HeLa-Kyoto cells transfected with control siRNA (B), 177 cells treated with doxycycline to induce expression and transfected with control siRNA (C), 178 untreated cells transfected with KIF22 siRNA (D), and cells treated with doxycycline and 179 transfected with KIF22 siRNA (E) normalized to the mean intensity of uninduced, control 180 knockdown cells (endogenous KIF22 expression level) for each cell line (B). 21-33 HeLa-Kyoto 181 cells per condition from 3 experiments. (F) DAPI-stained metaphase chromosome spreads from 182 uninduced RPE-1 cell lines with inducible expression of GFP, KIF22-GFP, KIF22-GFP R149Q, or 183 KIF22-GFP V475G. Scale bar $10 \mu \mathrm{m}$. Images are representative of 3 experiments. (G) Numbers 184 of chromosome pairs counted in metaphase spreads prepared from RPE-1 stable cell lines. 185 Dashed line indicates the expected chromosome number for diploid human cells (46). The mode 186 for each cell line is 46. 53-58 spreads per condition from 3 experiments. (H-K) Quantification of 187 KIF22 fluorescence intensity in untreated RPE-1 cells transfected with control siRNA $(H)$, cells 188 189 treated with doxycycline to induce expression and transfected with control siRNA (I), untreated cells transfected with KIF22 siRNA $(\mathrm{J})$, and cells treated with doxycycline and transfected with 190 KIF22 siRNA (K) normalized to the mean intensity of uninduced, control knockdown cells for each 191 cell line (H). 21-29 RPE-1 cells per condition from 3 experiments. For B-E and H-K, bars indicate 192 means. p values from Brown-Forsythe and Welch ANOVA with Dunnett's T3 multiple comparisons 193 test. $p$ values are greater than 0.05 for comparisons without a marked $p$ value. 


\section{Pathogenic mutations in KIF22 do not disrupt the localization of the motor}

To assess the effect of published pathogenic mutations in the motor domain and the novel pathogenic mutation in the tail on the function of KIF22 in mitosis, we generated human cervical adenocarcinoma (HeLa-Kyoto) cell lines with inducible expression of KIF22-GFP. Treatment of these cells with doxycycline induced KIF22-GFP expression at a level approximately two- to threefold higher than the level of expression of endogenous KIF22 as measured by immunofluorescence (Figure S1A-C). To facilitate both overexpression of and rescue with KIF22GFP constructs, siRNA-resistant silent mutations were introduced into exogenous KIF22 (Figure S1D-E). siRNA knockdown reduced levels of endogenous KIF22 by $87 \%$ (mean knockdown efficiency across HeLa-Kyoto cell lines) (Figure S1D). Initial experiments were performed using HeLa-Kyoto cell lines expressing each known pathogenic mutation in KIF22 (P148L, P148S, R149L, R149Q, and V475G), and a subset of experiments then focused on cells expressing one representative motor domain mutation $(\mathrm{R} 149 \mathrm{Q})$ or the coiled-coil domain mutation in the tail (V475G). Additionally, we generated inducible retinal pigmented epithelial (RPE-1) cell lines expressing wild type and mutant KIF22-GFP to assess any differences between the consequences of expressing mutant KIF22 in aneuploid cancer-derived cells (HeLa-Kyoto) and genomically stable somatic cells. RPE-1 cells are human telomerase reverse transcriptase (hTERT)-immortalized (Bodnar et al. 1998), and metaphase chromosome spreads demonstrated that these cell lines are near-diploid, with a modal chromosome number of 46 , even after selection to generate stable cell lines (Figure S1F-G). The expression level of siRNA-resistant KIF22-GFP in RPE-1 cell lines was approximately four- to seven-fold higher than the level of expression of endogenous KIF22 (Figure S1H-K), and siRNA knockdown reduced levels of endogenous KIF22 by $67 \%$ (mean knockdown efficiency across RPE-1 cell lines measured using immunofluorescence). As measurements of KIF22 depletion by immunofluorescence may include non-specific signal, this estimate of knockdown efficiency may underestimate the depletion of KIF22.

KIF22 localizes to the nucleus in interphase, and primarily localizes to chromosomes and spindle microtubules during mitosis (Tokai et al. 1996). KIF22-GFP with pathogenic mutations demonstrated the same localization pattern throughout the cell cycle as wild type motor (Figure 2A). In all cell lines, KIF22-GFP was localized to the nucleus in interphase cells and was bound to condensing chromosomes in prophase. In prometaphase, metaphase, and anaphase mutant and wild type KIF22-GFP localized primarily to chromosome arms, with a smaller amount of motor signal visible on the spindle microtubules. The same localization patterns were seen for mutant and wild type KIF22-GFP expressed in RPE-1 cells (Figure S2A). 
Since mutations did not grossly disrupt localization of KIF22-GFP, fluorescence recovery after photobleaching (FRAP) was used to compare the dynamics of mutant and wild type KIF22

230 localization. In interphase nuclei, KIF22-GFP signal recovered completely 220 seconds after 231 bleaching ( $97 \% \pm 3 \%$ of intensity before bleaching, mean \pm SEM), indicating a dynamic pool of 232 KIF22-GFP (Figure 2B and S2B). Similar high recovery percentages were also measured in 233 interphase nuclei of cells expressing KIF22-GFP R149Q and KIF22-GFP V475G (100\% \pm 6\% and $234103 \% \pm 7 \%$ at 220 seconds, respectively) (Figure 2E and 2H). In contrast, KIF22-GFP recovery 235 was minimal in cells bleached during metaphase and anaphase. In metaphase cells, immediately 236 after bleaching KIF22-GFP intensity was reduced to $18 \pm 3 \%$ of initial intensity, and intensity had 237 recovered to only $25 \% \pm 3 \%$ after 220 seconds (Figure 2C and S2B). In anaphase, KIF22-GFP 238 intensity immediately after bleaching was $17 \% \pm 2 \%$ of initial intensity, and intensity recovered to $23935 \% \pm 6 \%$ of initial intensity after 220 seconds (Figure 2D and S2B). This limited recovery 240 indicates that KIF22 stably associates with mitotic chromosomes. Pathogenic mutations did not 241 change these localization dynamics; recovery percentages in mitosis were also low in cells 242 expressing KIF22-GFP R149Q (32 $\pm 3 \%$ of initial intensity in metaphase 220 seconds after 243 bleaching, $39 \pm 6 \%$ in anaphase) (Figure 2F and 2G) and KIF22-GFP V475G (29 $\pm 2 \%$ of initial 244 intensity in metaphase, $35 \pm 6 \%$ in anaphase) (Figure $2 \mathbf{l}$ and $2 \mathbf{J}$ ). These data indicate that 245 pathogenic mutations do not alter the localization of KIF22 to chromosomes and spindle 246 microtubules, and do not alter KIF22 localization dynamics in interphase, metaphase, or 247 anaphase. 
bioRxiv preprint doi: https://doi.org/10.1101/2021.09.29.462402; this version posted November 19, 2021. The copyright holder for this preprint (which was not certified by peer review) is the author/funder, who has granted bioRxiv a license to display the preprint in perpetuity. It is made available under aCC-BY 4.0 International license.

Figure 2
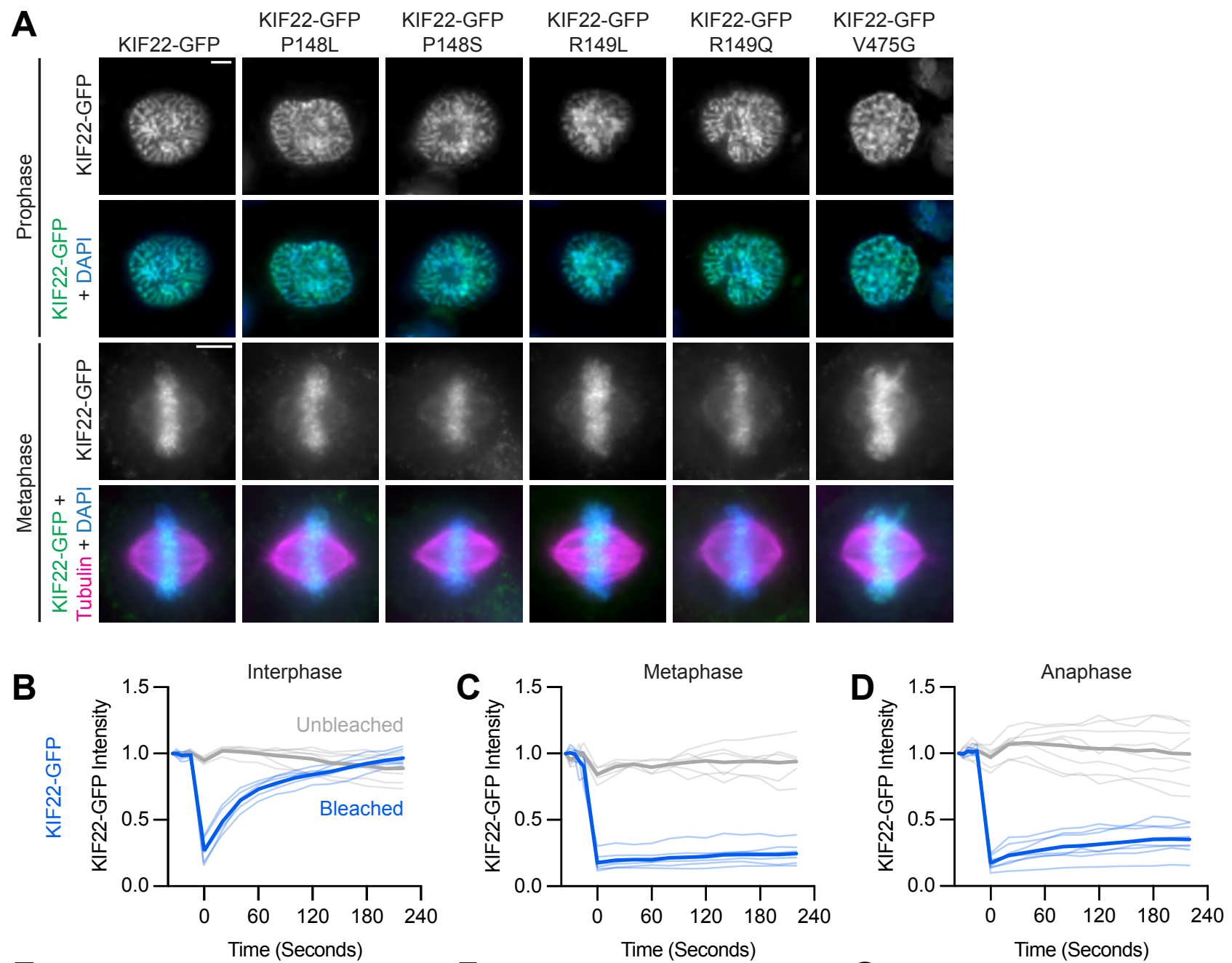

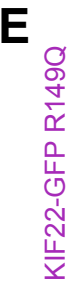
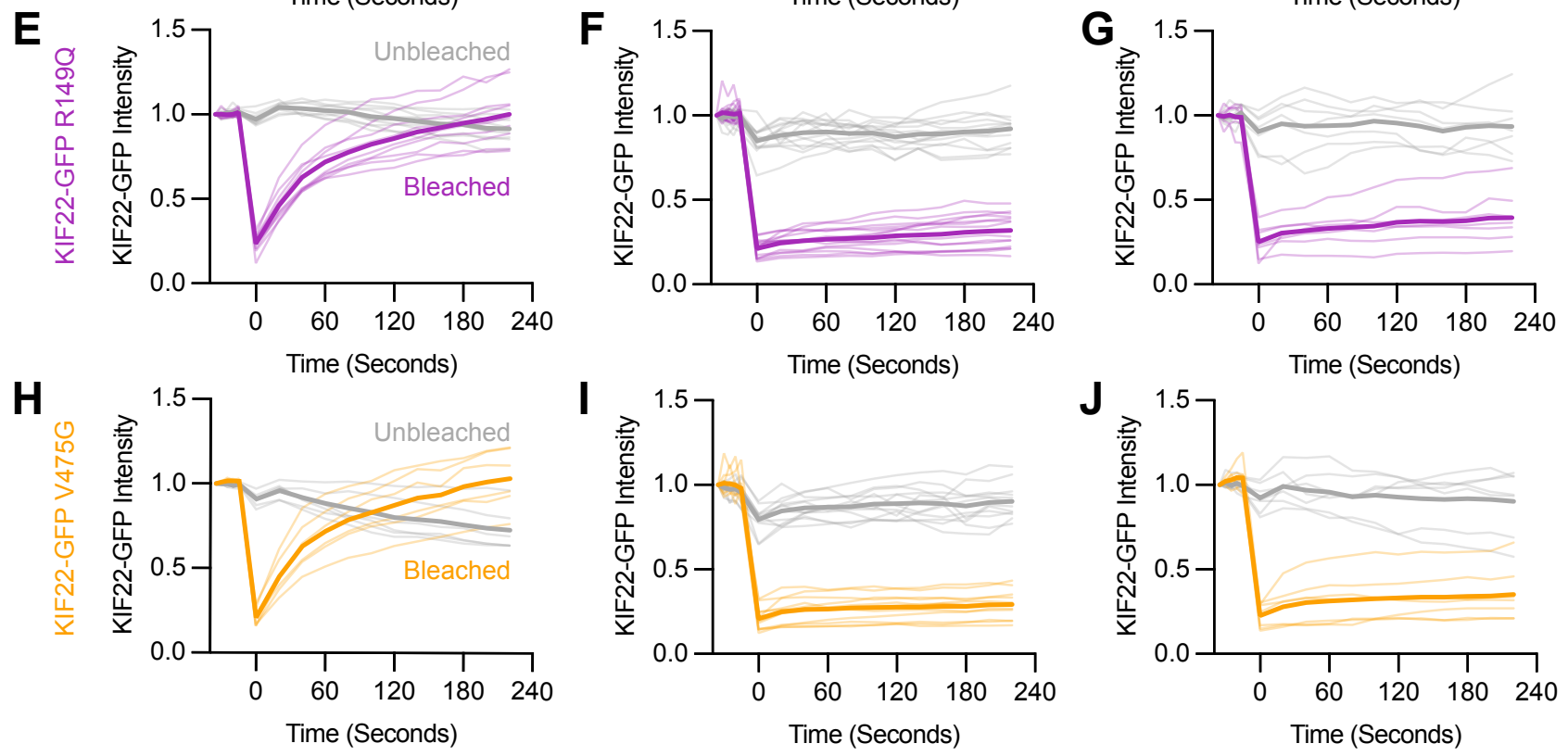


\section{Figure 2. Pathogenic mutations in KIF22 do not disrupt the localization of the motor.}

249 (A) Immunofluorescence images of HeLa-Kyoto cells expressing KIF22-GFP constructs in

250 prophase (top two rows) and metaphase (bottom two rows). KIF22-GFP was visualized using an

251 anti-GFP antibody. Images are maximum intensity projections in $z$ of five frames at the center of

252 the spindle (metaphase cells) or maximum intensity projections in $z$ of two frames (prophase

253 cells). Fixed approximately 24 hours after treatment with doxycycline to induce expression. Scale

254 bars $5 \mu \mathrm{m}$. (B-J) Fluorescence recovery after photobleaching (FRAP) of KIF22-GFP (B-D), KIF22-

255 GFP R149Q (E-G), and KIF22-GFP V475G (H-J) in interphase nuclei (B, E, H) or on metaphase

$256(\mathrm{C}, \mathrm{F}, \mathrm{I})$ or anaphase $(\mathrm{D}, \mathrm{G}, \mathrm{J})$ chromosomes. Bleaching occurred at time zero. Thin lines are

257 traces from individual cells and thick lines represent means. Intensity values are normalized to

258 the KIF22-GFP intensity in the first imaged frame before bleaching. 6-14 cells from 3-5

259 experiments per condition. 
bioRxiv preprint doi: https://doi.org/10.1101/2021.09.29.462402; this version posted November 19, 2021. The copyright holder for this preprint (which was not certified by peer review) is the author/funder, who has granted bioRxiv a license to display the preprint in perpetuity. It is made available under aCC-BY 4.0 International license.

\section{Supplemental Figure 2}

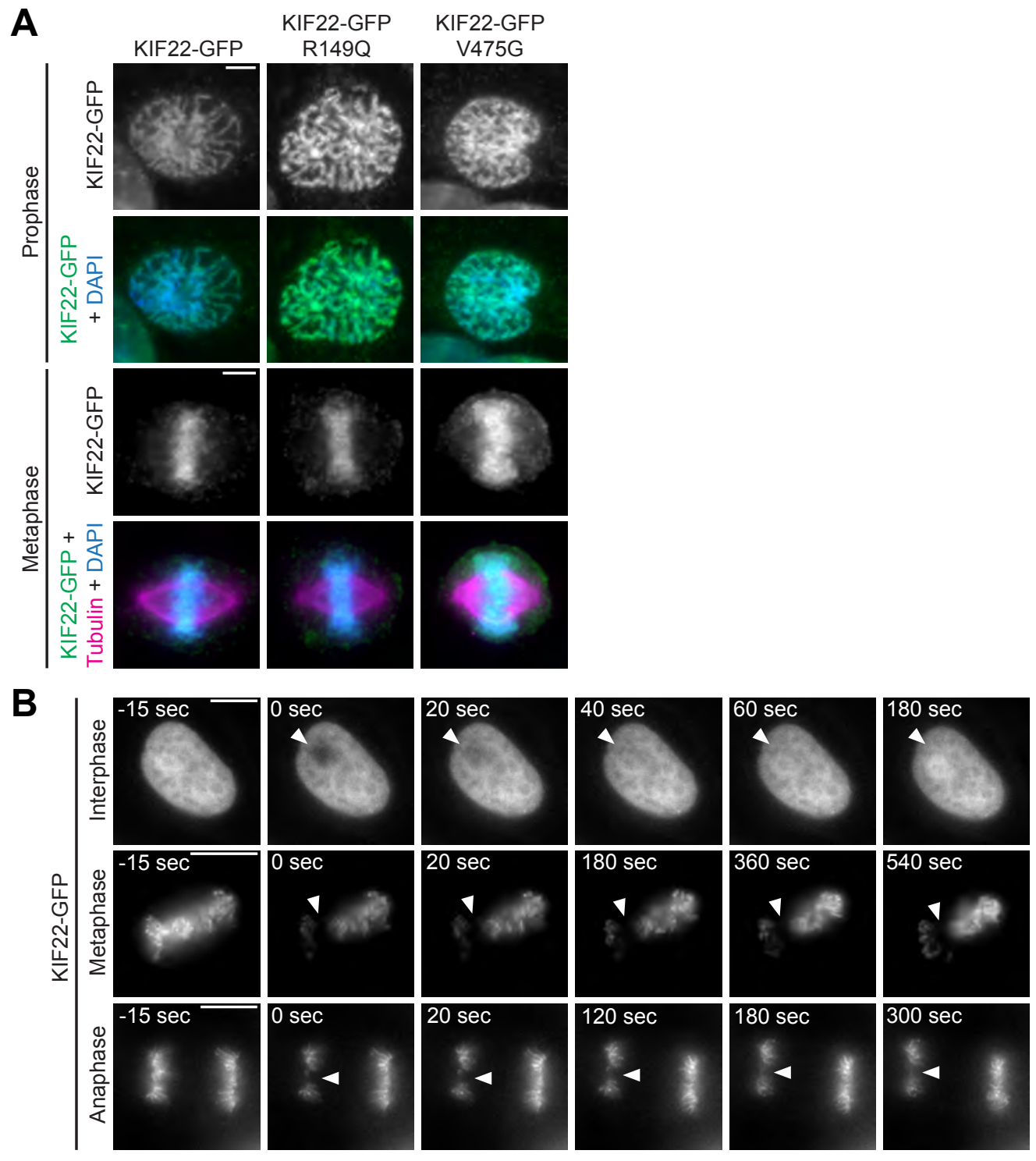


260 Supplemental Figure 2. Pathogenic mutations in KIF22 do not disrupt the localization of 261 the motor in RPE-1 cells.

262 (A) Immunofluorescence images of RPE-1 cells expressing KIF22-GFP constructs in prophase

263 (top two rows) and metaphase (bottom two rows). KIF22-GFP was visualized using an anti-GFP

264 antibody. Images are maximum intensity projections in $z$ of five frames at the center of the spindle

265 (metaphase cells) or maximum intensity projections in $z$ of three frames (prophase cells). Fixed

266 approximately 18 hours after treatment with doxycycline to induce expression. Scale bars $5 \mu \mathrm{m}$.

267 (B) Time-lapse images of fluorescence recovery after photobleaching (FRAP) in HeLa-Kyoto cells

268 expressing KIF22-GFP. Bleaching occurred at time zero, and arrowheads indicate bleached area.

269 Scale bars $10 \mu \mathrm{m}$. Images are representative of 3 or more experiments. 


\section{Mutations do not reduce polar ejection forces}

In prometaphase and metaphase, KIF22 contributes to chromosome congression and

272 alignment by generating polar ejection forces (Levesque and Compton 2001; Stumpff et al. 2012;

273 Brouhard and Hunt 2005; Wandke et al. 2012). In cells treated with monastrol to inhibit Eg5/KIF11

274 and generate monopolar spindles, polar ejection forces push chromosomes away from a single

275 central spindle pole (Levesque and Compton 2001) (Figure 3A). A loss of KIF22 function causes

276 chromosomes to collapse in towards the pole in this system (Levesque and Compton 2001)

277 (Figure 3A). To determine whether overexpression of KIF22-GFP with pathogenic mutations has

278 a dominant effect on polar ejection force generation, wild type or mutant KIF22-GFP-expressing

279 HeLa-Kyoto cells were treated with monastrol to induce mitotic arrest with monopolar spindles.

280 Relative polar ejection forces were compared by measuring the distance from the spindle pole to

281 the maximum DAPI signal (Figure 3A). Expression of mutant motor did not reduce polar ejection

282 forces (Figure 3B and 3C). Rather, expression of KIF22-GFP R149L and R149Q significantly

283 increased the distance from the pole to the maximum DAPI signal (R149L 4.6 $\pm 0.13 \mu \mathrm{m}, \mathrm{R} 149 \mathrm{Q}$

$2844.3 \pm 0.11 \mu \mathrm{m}$, GFP control $3.7 \pm 0.04 \mu \mathrm{m}$, mean \pm SEM), indicating higher levels of polar ejection

285 forces in these cells.

286 The same assay was used to test whether mutant KIF22 could rescue polar ejection force 287 generation in cells depleted of endogenous KIF22. In control cells expressing GFP, depletion of 288 endogenous KIF22 resulted in the collapse of chromosomes towards the pole (Figure 3B), and 289 the distance from the pole to the maximum DAPI signal was reduced to $1.6 \pm 0.11 \mu \mathrm{m}$, indicating 290 a loss of polar ejection forces (Figure 3D). This reduction was not observed in cells expressing 291 wild type or mutant KIF22-GFP, demonstrating that KIF22-GFP with pathogenic mutations is 292 capable of generating polar ejection forces (Figure 3B and 3D). In cells transfected with control 293 siRNA and cells depleted of endogenous KIF22, polar ejection force levels did not depend on 294 KIF22-GFP expression levels (Figure 3E and 3F).

295 Together, the localization of mutant KIF22 and the ability of mutant KIF22 to generate 296 polar ejection forces indicate that pathogenic mutations P148L, P148S, R149L, R149Q, and 297 V475G do not result in a loss of KIF22 function during early mitosis. 
bioRxiv preprint doi: https://doi.org/10.1101/2021.09.29.462402; this version posted November 19, 2021. The copyright holder for this preprint

(which was not certified by peer review) is the author/funder, who has granted bioRxiv a license to display the preprint in perpetuity. It is made available under aCC-BY 4.0 International license.

Figure 3
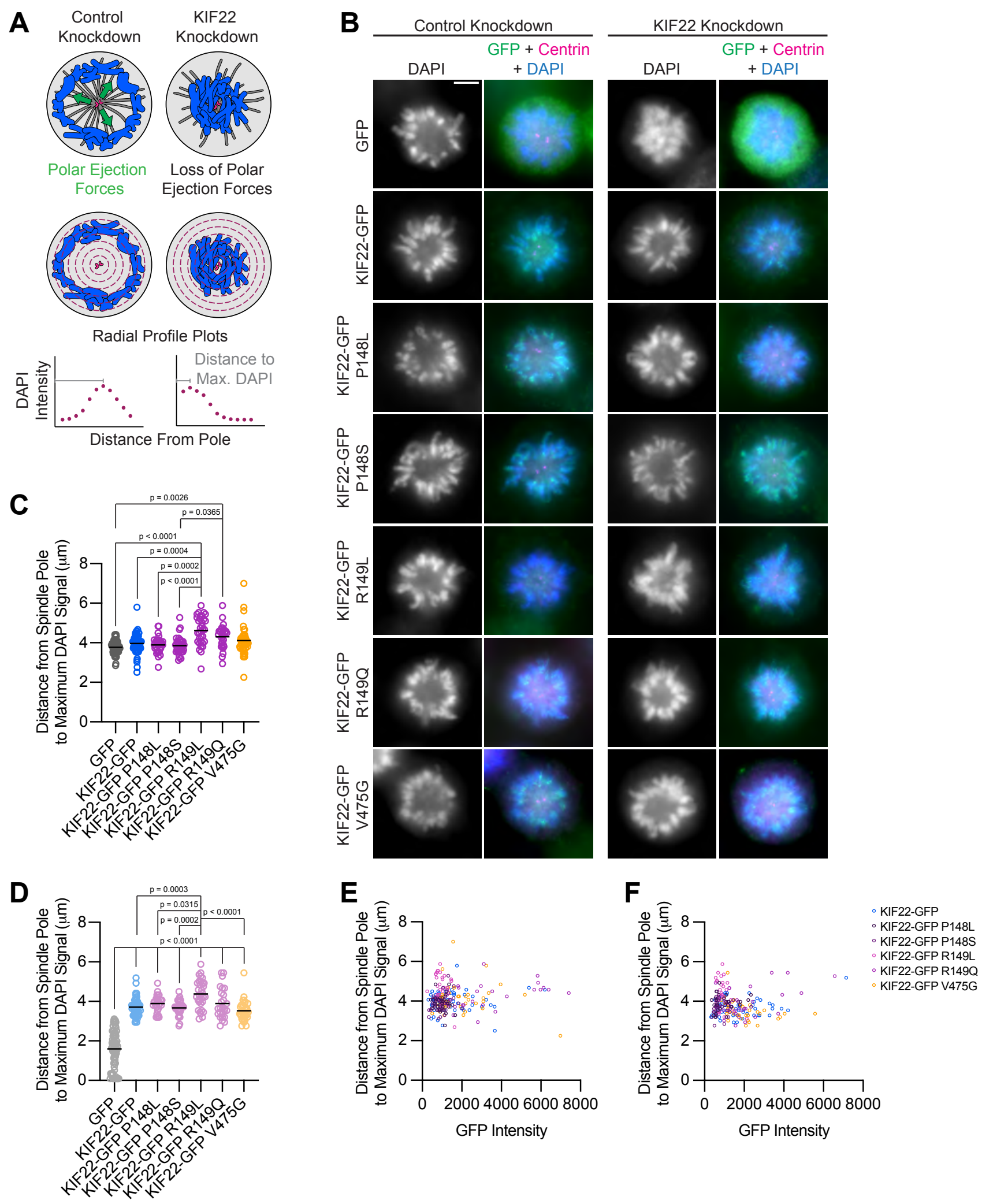


\section{Figure 3. Pathogenic mutations in KIF22 do not reduce polar ejection forces.}

299 (A) Schematic of changes in chromosome positions resulting from loss of polar ejection forces.

300 In cells with monopolar spindles, both spindle poles (magenta) are positioned together and 301 chromosomes (blue) are pushed toward the cell periphery by polar ejection forces (green) (left).

302 In cells depleted of KIF22, polar ejection forces are reduced and chromosomes collapse in toward 303 the center of the cell (right). Relative polar ejection forces were quantified using radial profile plots 304 to measure the distance from the spindle pole to the maximum DAPI signal intensity. (B) 305 Immunofluorescence images of monopolar HeLa-Kyoto cells. KIF22-GFP was visualized using 306 an anti-GFP antibody. Fixed approximately 2-3 hours after treatment with monastrol and 24 hours 307 after siRNA transfection and treatment with doxycycline to induce expression. Scale bar $5 \mu \mathrm{m}$. 308 Images are representative of 3 or more experiments. (C) Distance from the spindle pole to the 309 maximum DAPI signal, a measure of relative polar ejection force level, in cells transfected with 310 control siRNA. 28-69 cells from 3-7 experiments per condition. (D) Distance from the spindle pole 311 to the maximum DAPI signal in cells transfected with KIF22 siRNA. 26-75 cells from 3-7 312 experiments per condition. For C-D, bars indicate means. $p$ values from Brown-Forsythe and 313 Welch ANOVA with Dunnett's T3 multiple comparisons test. $p$ values are greater than 0.05 for 314 comparisons without a marked $p$ value. (E-F) Background-subtracted GFP intensity plotted 315 against the distance from the spindle pole to the maximum DAPI signal to assess dependence of 316 polar ejection force generation on expression levels in cells transfected with control siRNA (E) 317 (Pearson correlation coefficient 0.105, two-tailed $p$ value 0.1031) or KIF22 siRNA (F) (Pearson 318 correlation coefficient -0.005 , two-tailed $p$ value 0.9427 ). 


\section{KIF22 mutations disrupt anaphase chromosome segregation}

While pathogenic mutations did not disrupt the function of KIF22 in prometa- or metaphase, HeLa-Kyoto cells expressing mutant KIF22-GFP exhibited defects in anaphase chromosome segregation. In these cells, chromosomes did not move persistently towards the spindle poles. Instead, chromosomes began to segregate, but then reversed direction and moved back towards the center of the spindle or remained in the center of the spindle until decondensation (Figure 4A). This phenotype was dominant and occurred in the presence of endogenous KIF22. Recongression was quantified by measuring the distance between separating chromosome masses as anaphase progressed. In cells expressing wild type KIF22GFP, this value increases steadily and then plateaus. Expression of mutant KIF22-GFP causes the distance between chromosome masses to increase, then decrease as chromosomes recongress, and then increase again as segregation continues (Figure 4B). Recongression reduces the distance between chromosome masses 7 minutes after anaphase onset in cells expressing KIF22-GFP with pathogenic mutations (median distance $2.0-7.2 \mu \mathrm{m}$ ) compared to cells expressing wild type KIF22-GFP (median distance $12.9 \mu \mathrm{m}$ ) (Figure 4C). Defects in anaphase chromosome segregation were also observed in RPE-1 cells expressing KIF22-GFP R149Q or V475G (Figure S3D, S3E, S3F). This gain of function phenotype is consistent with a lack of KIF22 inactivation in anaphase, resulting in a failure to suspend polar ejection force generation.

If recongression is the result of increased KIF22 activity in anaphase, we would predict that increased levels of KIF22-GFP expression would cause more severe anaphase chromosome segregation defects. Indeed, plotting the distance between chromosome masses 7 minutes after anaphase onset against mean GFP intensity for each HeLa-Kyoto cell demonstrated that these two values were correlated (Spearman correlation coefficient -0.6246 , one-tailed $p$ value < 0.0001) (Figure S3A). Considering only cells expressing lower levels of KIF22-GFP (mean background subtracted intensity $<100$ arbitrary units) emphasized the differences in the distance between chromosome masses as anaphase progressed between cells expressing wild type and mutant motor (Figure S3B, S3C).

In a subset of HeLa-Kyoto cells, expression of KIF22-GFP with pathogenic mutations caused cytokinesis failure (Figure 4D). In these cells, cleavage furrow ingression began, but did not complete, resulting in a single daughter cell. The percentage of cells failing to complete cytokinesis was approximately ten-fold higher in cells expressing mutant KIF22-GFP (R149Q $36 \%$, V475G 25\%) than in cells expressing wild type KIF22-GFP (3\%). Additionally, the distance between chromosome masses at the time of cleavage furrow ingression was reduced in cells 
353 expressing KIF22-GFP R149Q or V475G, suggesting that the position of the chromosome 354 masses may be physically obstructing cytokinesis (Figure 4E). Consistent with this hypothesis, 355 cells that failed to complete cytokinesis tended to have lower distances between chromosome 356 masses than the distances measured in cells in which cytokinesis completed despite expression 357 of mutant KIF22-GFP (Figure 4E). 
bioRxiv preprint doi: https://doi.org/10.1101/2021.09.29.462402; this version posted November 19, 2021. The copyright holder for this preprint

(which was not certified by peer review) is the author/funder, who has granted bioRxiv a license to display the preprint in perpetuity. It is made available under aCC-BY 4.0 International license.

Figure 4
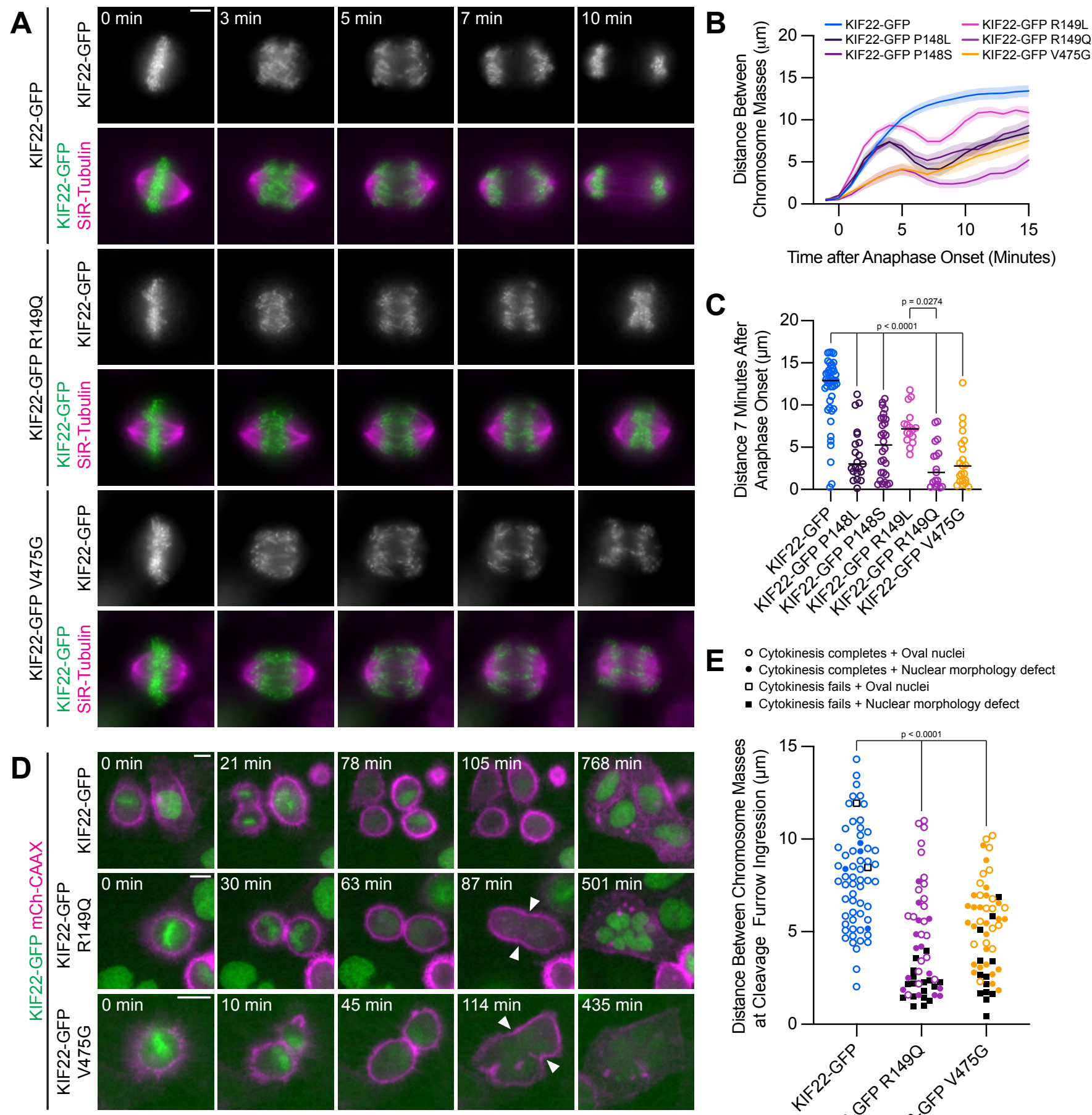

Time after Anaphase Onset (Minutes)

C
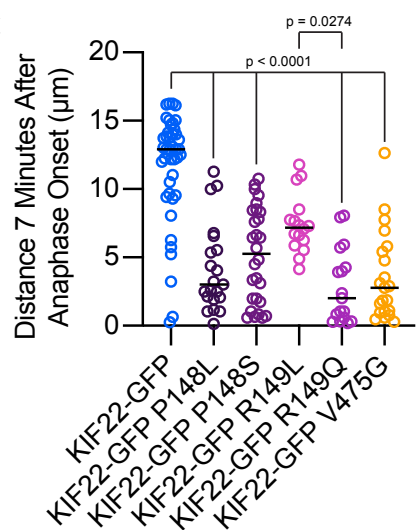

E Cytokinesis completes + Oval nuclei

- Cytokinesis completes + Nuclear morphology defect a Cytokinesis fails + Oval nuclei

- Cytokinesis fails + Nuclear morphology defect

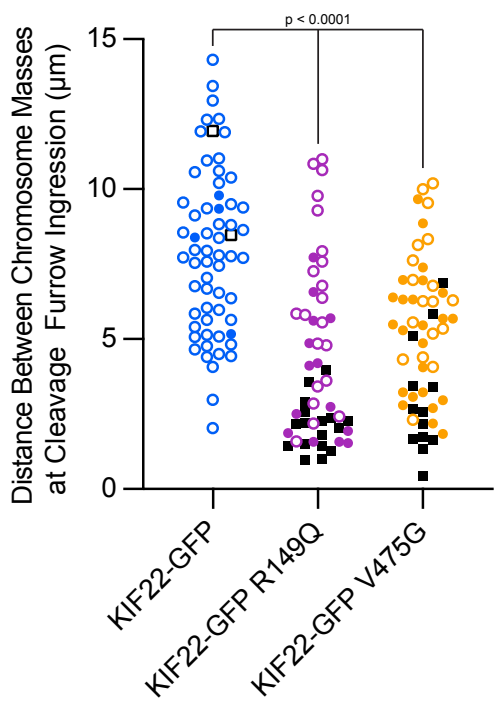




\section{Figure 4. Pathogenic mutations in KIF22 disrupt anaphase chromosome segregation.}

359 (A) Time-lapse images of dividing HeLa-Kyoto cells expressing KIF22-GFP R149Q or KIF22-GFP

360 V475G. Times indicate minutes after anaphase onset. Images are maximum intensity projections

361 in $z$ through the entirety of the spindle. Imaged approximately 18 hours after treatment with

362 doxycycline to induce expression. Scale bar $5 \mu \mathrm{m}$. Images are representative of 3 or more

363 experiments. (B) Distance between separating chromosome masses throughout anaphase in

364 HeLa-Kyoto cells. Lines represent the mean and the shaded area denotes SEM. 16-43 cells from

365 4-10 experiments per condition. (C) Distance between separating chromosome masses 7 minutes

366 after anaphase onset. Bars indicate medians. $p$ values from Kruskal-Wallis test. $p$ values are

367 greater than 0.05 for comparisons without a marked $p$ value. 16-43 cells from 4-10 experiments

368 per condition. (D) Time-lapse images of dividing HeLa-Kyoto cells expressing mCherry (mCh)-

369 CAAX to visualize cell boundaries. Times indicate minutes after anaphase onset. Arrowheads

370 indicate cytokinesis failure. Imaged approximately 8 hours after treatment with doxycycline to

371 induce expression and 24-32 hours after transfection with mCh-CAAX. Scale bars $20 \mu \mathrm{m}$. Images

372 are representative of 3 or more experiments. (E) Distance between chromosome masses at the

373 time of cleavage furrow ingression. $p$ values from Kruskal-Wallis test. $p$ values are greater than

3740.05 for comparisons without a marked $p$ value. 52-62 cells from 9-10 experiments per condition. 
bioRxiv preprint doi: https://doi.org/10.1101/2021.09.29.462402; this version posted November 19, 2021. The copyright holder for this preprint

(which was not certified by peer review) is the author/funder, who has granted bioRxiv a license to display the preprint in perpetuity. It is made available under aCC-BY 4.0 International license.

\section{Supplemental Figure 3}
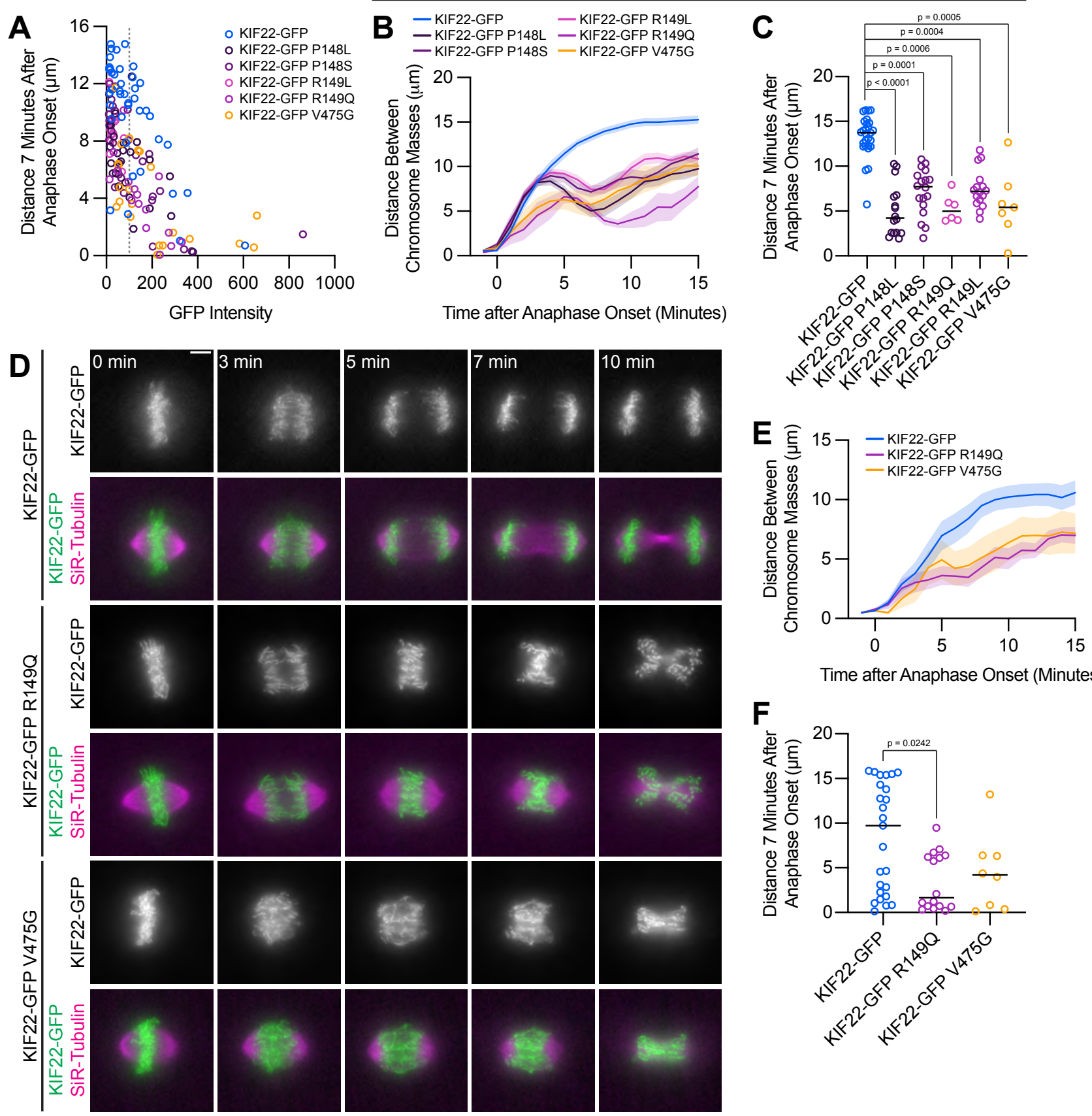
375 Supplemental Figure 3. Anaphase recongression defects are KIF22-GFP expression level 376 dependent and disrupt chromosome segregation in RPE1 cells.

377 (A) Background-subtracted GFP intensity plotted against the distance between separating 378 chromosome masses at 7 minutes to assess dependence of recongression on expression level 379 (Spearman correlation coefficient -0.6246 , one-tailed $p$ value $<0.0001$ ). Grey dashed line 380 indicates mean background subtracted GFP intensity of 100. 16-43 cells from 4-10 experiments 381 per condition. (B) Distance between separating chromosome masses of cells expressing lower 382 levels of KIF22-GFP (mean background subtracted GFP intensity less than 100). Lines represent 383 the mean and the shaded area denotes SEM. 6-24 cells from 3-8 experiments per condition. (C) 384 Distance between separating chromosome masses 7 minutes after anaphase onset of cells 385 expressing lower levels of KIF22-GFP (mean background subtracted GFP intensity less than 386 100). Bars indicate medians. $p$ values from Kruskal-Wallis test. $p$ values are greater than 0.05 for 387 comparisons without a marked $p$ value. 6-24 cells from 3-8 experiments per condition. (D) Time388 lapse images of dividing RPE-1 cells expressing KIF22-GFP R149Q or KIF22-GFP V475G. 389 Imaged approximately 12-18 hours after treatment with doxycycline to induce expression. Times 390 indicate minutes after anaphase onset. Images are maximum intensity projections in $z$ through 391 the entirety of the spindle. Scale bar $5 \mu \mathrm{m}$. Images are representative of 3 or more experiments. 392 (E) Distance between separating chromosome masses throughout anaphase in RPE-1 cells. 393 Lines represent the mean and the shaded area denotes SEM. 8-25 cells from 6-7 experiments 394 per condition. (F) Distance between separating chromosome masses 7 minutes after anaphase 395 onset in RPE-1 cells. Bars indicate medians. $p$ value from Kruskal-Wallis test. $p$ values are greater 396 than 0.05 for comparisons without a marked $p$ value. 8-25 cells from 6-7 experiments per 397 condition. 
Mutations disrupt the separation of the spindle poles in anaphase

Anaphase chromosome segregation requires both that chromosome arms and centromeres move towards the spindle poles (anaphase A) (Asbury 2017) and that the spindle poles move away from one another (anaphase B) (Ris 1949). To test whether the activity of

402 mutant KIF22 in anaphase affects one or both of these processes, anaphase was imaged in HeLa-

403 Kyoto cells expressing fluorescent markers for the poles (pericentrin-RFP) and centromeres

404 (CENPB-mCh) (Figure 5A). The reduced distance between separating chromosome masses

405 seen in these cells (Figure 5B, 5C) was compared to the distances between the centromeres

406 (Figure 5D, 5E) and the distances between the poles (Figure 5F, 5G) as anaphase progressed.

407 The distances between all three structures showed the same trend: in cells expressing wild type

408 KIF22-GFP, the distance between chromosome masses, between centromeres, and between the

409 spindle poles increased throughout the measured time interval in anaphase. Pathogenic

410 mutations altered the movements of all three structures (Figure 5B, 5D, 5F). The distance

411 between chromosome masses, between centromeres, and between the spindle poles 10 minutes

412 after anaphase onset was significantly reduced in cells expressing KIF22-GFP R149Q (Figure

413 5C, 5E, 5G). In cells expressing KIF22-GFP V475G, the same trend was observed, but the 414 reductions in distance were not statistically significant. Comparing the distance between 415 chromosome masses and the spindle pole within each half spindle (Figure $\mathbf{5 H}$ ) with the distance 416 between centromeres and the spindle pole in the same half spindles (Figure 5I) demonstrated 417 that expression of mutant KIF22 more potently reduced the segregation of chromosome arms 418 than centromeres, consistent with continued generation of polar ejection forces in anaphase. This 419 suggests that pathogenic mutations in KIF22 affect anaphase A by altering the movement of 420 chromosome arms, but not the shortening of the k-fibers, and affect anaphase B by altering 421 spindle pole separation. 
bioRxiv preprint doi: https://doi.org/10.1101/2021.09.29.462402; this version posted November 19, 2021. The copyright holder for this preprint

(which was not certified by peer review) is the author/funder, who has granted bioRxiv a license to display the preprint in perpetuity. It is made available under aCC-BY 4.0 International license.

Figure 5

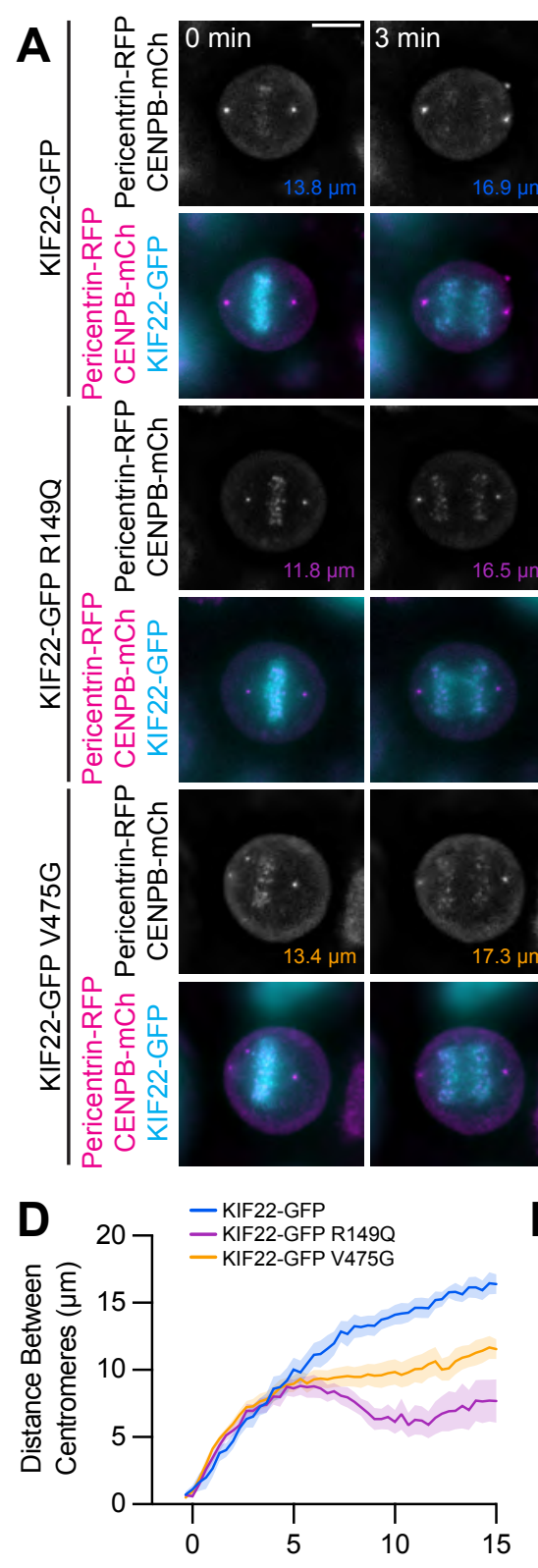

Time after Anaphase Onset (Minutes)
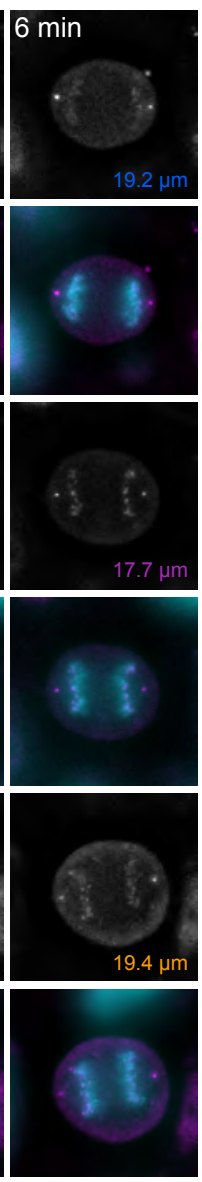
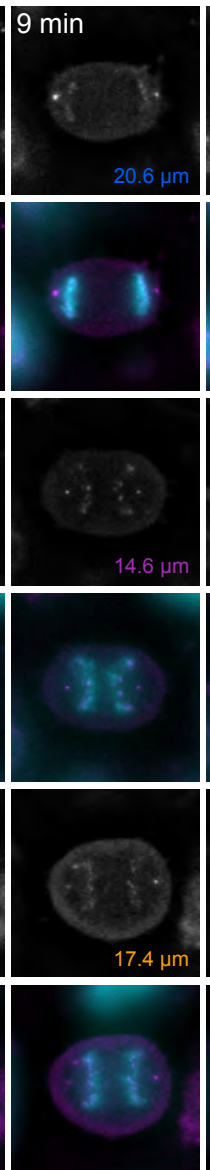

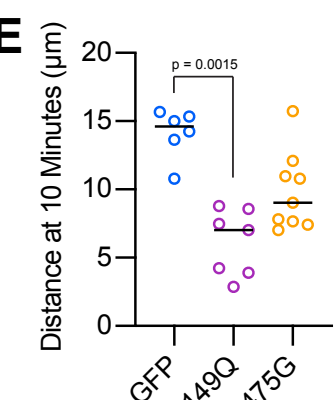

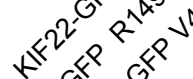
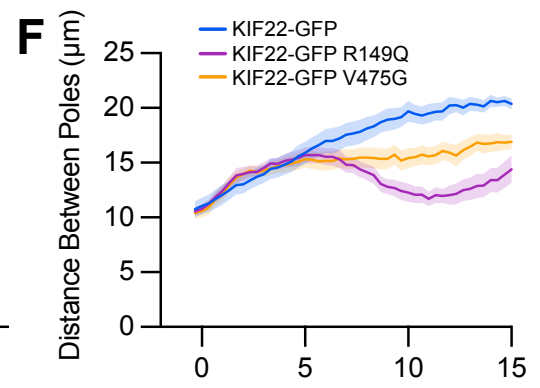

Time after Anaphase Onset (Minutes)

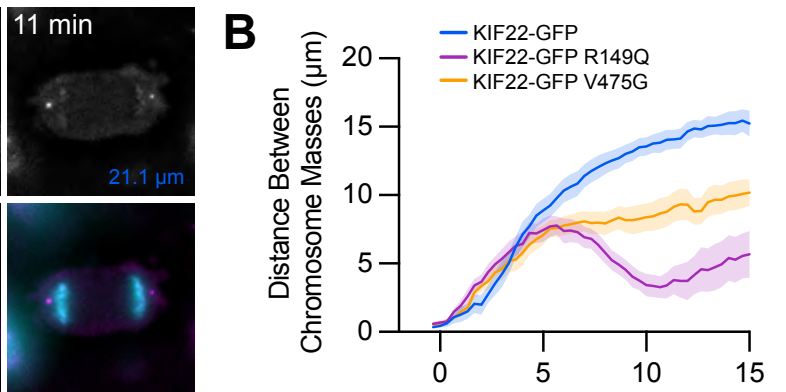

Time after Anaphase Onset (Minutes)

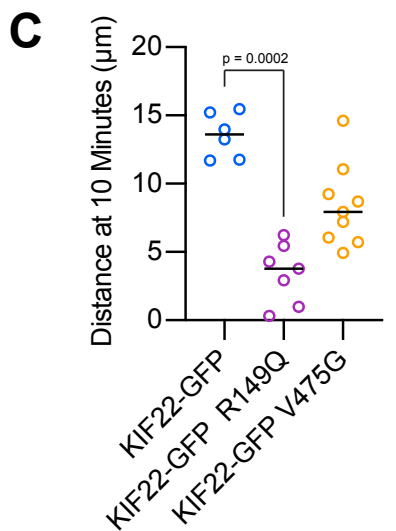

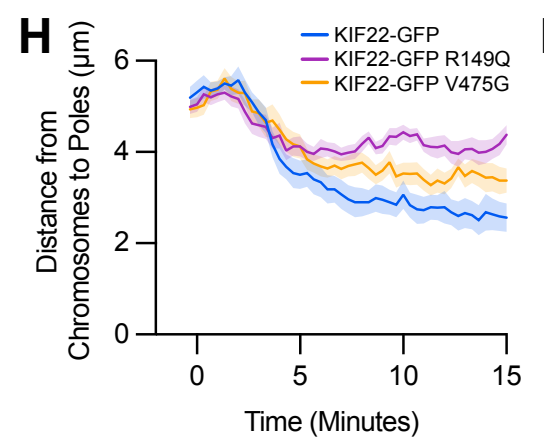
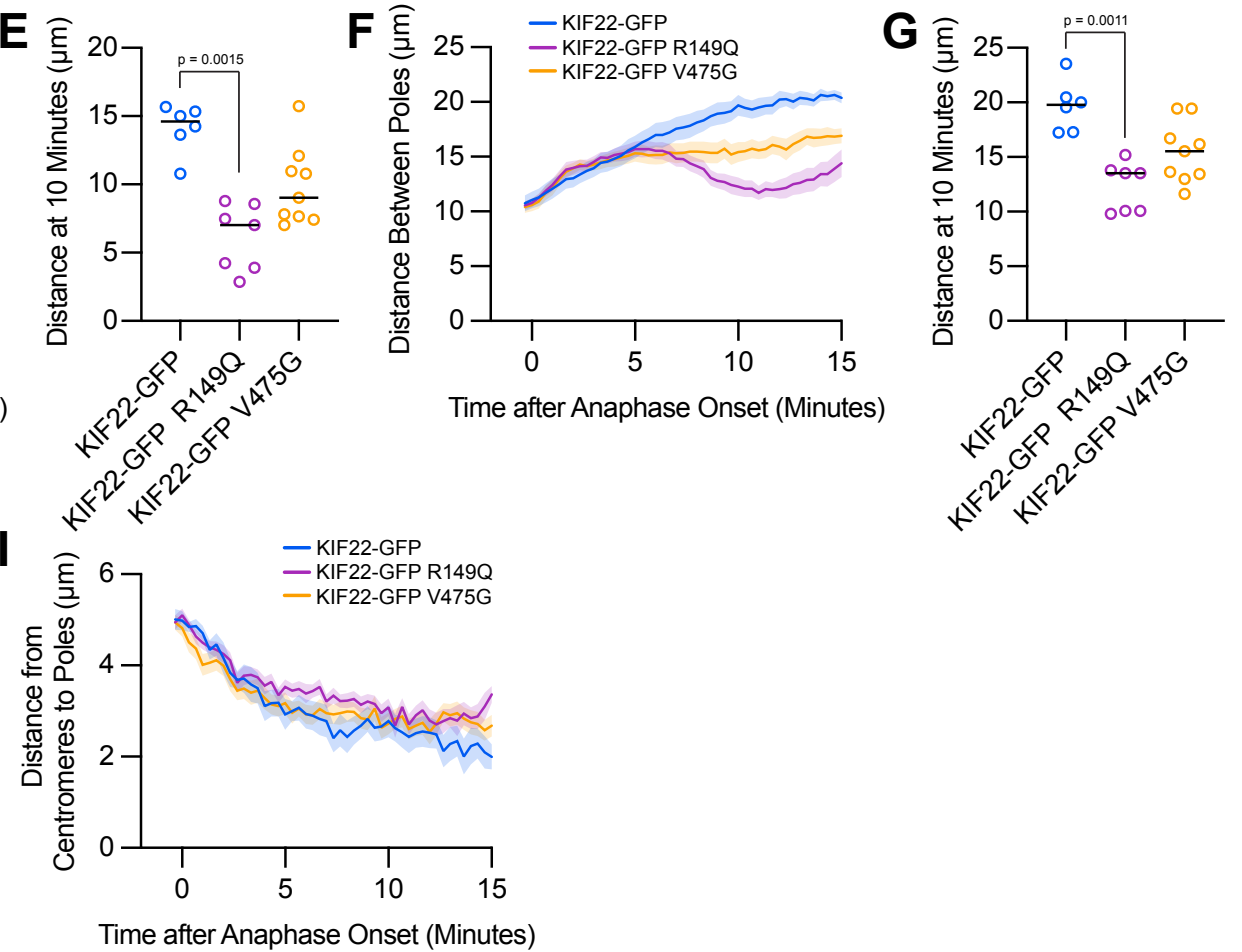
422 Figure 5. Mutations disrupt the separation of spindle poles in anaphase.

423 (A) Time-lapse images of dividing HeLa-Kyoto cells expressing pericentrin-RFP to mark the 424 spindle poles and CENPB-mCh to mark centromeres. Times indicate minutes after anaphase 425 onset. Colored distances in the bottom right of each greyscale image indicate the distance 426 between the spindle poles in the image. Images are maximum intensity projections in $z$ through 427 the entirety of the spindle. Imaged approximately 24 hours after transfection and 12-18 hours after 428 treatment with doxycycline to induce expression. Images depicting pericentrin-RFP and CENPB$429 \mathrm{mCh}$ signal were background subtracted by duplicating each frame, applying a gaussian blur 430 (sigma 30 pixels), and subtracting this blurred image from the original. Scale bar $10 \mu \mathrm{m}$. Images 431 are representative of 3 or more experiments. (B) Distance between separating chromosome 432 masses throughout anaphase in HeLa-Kyoto cells. Lines represent the mean and the shaded 433 area denotes SEM. (C) Distance between separating chromosome masses 10 minutes after 434 anaphase onset in HeLa-Kyoto cells. Bars indicate medians. (D) Distance between centromeres 435 (CENPB-mCh) throughout anaphase in HeLa-Kyoto cells. Lines represent the mean and the 436 shaded area denotes SEM. (E) Distance between centromeres 10 minutes after anaphase onset 437 in HeLa-Kyoto cells. Bars indicate medians. (F) Distance between spindle poles (pericentrin-RFP) 438 throughout anaphase in HeLa-Kyoto cells. Lines represent the mean and the shaded area 439 denotes SEM. (G) Distance between spindle poles 10 minutes after anaphase onset in HeLa440 Kyoto cells. Bars indicate medians. Measurements from the same cells (6-9 cells from 3 441 experiments per condition) are shown in B-G. For C, E, and G, p values from Kruskal-Wallis test. $442 p$ values are greater than 0.05 for comparisons without a marked $p$ value. $(\mathbf{H})$ Distance between 443 chromosome masses and spindle poles throughout anaphase in HeLa-Kyoto cells. Lines 444 represent the mean and the shaded area denotes SEM. (I) Distance between centromeres and 445 spindle poles throughout anaphase in HeLa-Kyoto cells. Lines represent the mean and the 446 shaded area denotes SEM. Measurements from the same cells (12-18 half-spindle 447 measurements from 3 experiments per condition) as in B-G are shown in $\mathrm{H}$ and I. 
Division of cells expressing KIF22 with pathogenic mutations results in daughter cells with abnormally shaped nuclei

To understand the consequences of the observed defects in anaphase chromosome segregation, we examined the daughter cells produced by the division of cells expressing KIF22GFP with pathogenic mutations. In these cells, the nuclei are lobed and fragmented (Figure 6A). The percentage of divisions resulting in nuclear morphology defects was approximately ten-fold higher than in control cells (KIF22-GFP 6\%, KIF22-GFP R149Q 64\%, KIF22-GFP V475G 68\%) when live divisions were observed (Figure 4E). To further quantify this phenotype, the solidity of fixed cell nuclei (the ratio of the area of each nucleus to the area of the convex shape that would enclose it) was measured. A perfectly oval nucleus would have a solidity value of one. Solidity values were reduced in cells expressing KIF22-GFP with pathogenic mutations (Figure 6B), indicating that these cells had more irregularly shaped nuclei. This reduction in solidity was dominant and occurred both in the presence of endogenous KIF22 and when endogenous KIF22 was depleted via siRNA knockdown. Using the fifth percentile solidity of control cells (control knockdown, GFP expression) as a cut-off, 44-63\% of cells expressing mutant KIF22-GFP had abnormally shaped nuclei 24 hours after treatment with doxycycline to induce expression of KIF22-GFP (Figure 6C). Expression of wild type KIF22-GFP also resulted in a small increase in the percentage of cells with abnormally shaped nuclei $(12 \%)$. This percentage was reduced when endogenous KIF22 was depleted (7\%), consistent with nuclear morphology defects resulting from an increase in KIF22 activity.

Expression of KIF22-GFP with pathogenic mutations also caused abnormally shaped nuclei in RPE-1 cells (Figure S4A). The solidity of nuclei in cells expressing mutant KIF22-GFP was reduced (Figure S4B), and $40-49 \%$ of RPE-1 cells expressing mutant KIF22-GFP had abnormally shaped nuclei, again defined as a solidity value less than the fifth percentile of control cells (Figure 4C). In RPE-1 cells, expression of wild type KIF22-GFP resulted in a higher percentage of cells with abnormally shaped nuclei (18\% in control knockdown cells, $15 \%$ with KIF22 knockdown) than was seen in HeLa-Kyoto cells. This may be a result of the higher expression level of KIF22-GFP in the RPE-1 inducible cell lines (Figure S1I, S1K).

To determine whether these nuclear morphology defects depended on the ability of KIF22

477 to generate forces within the mitotic spindle, cells were treated with nocodazole to depolymerize 478 microtubules and reversine to silence the spindle assembly checkpoint, allowing cells to enter 479 and exit mitosis without assembling a spindle or segregating chromosomes (Samwer et al. 2017; 480 Serra-Marques et al. 2020) (Figure 6D). The solidity of nuclei was measured before 481 chromosomes condensed (Figure 6E) and after mitotic exit (Figure 6F). At both time points, there 
482 was no difference in nuclear shape between control cells and cells expressing KIF22-GFP with 483 pathogenic mutations, indicating that the effects of mutations on nuclear structure are spindle484 dependent.

485 The effect of nuclear morphology defects on daughter cell fitness may partially depend on 486 whether the nuclear envelopes of abnormally shaped nuclei are intact. The expression of mCherry 487 ( $\mathrm{mCh}$ ) with a nuclear localization signal (NLS) indicated that even highly lobed and fragmented 488 nuclei in cells expressing mutant KIF22-GFP are capable of retaining nuclear-localized proteins 489 (Figure 6G). This suggests that the nuclear envelopes of these abnormally shaped nuclei are still 490 intact enough to function as a permeability barrier (Hatch et al. 2013). 
bioRxiv preprint doi: https://doi.org/10.1101/2021.09.29.462402; this version posted November 19, 2021. The copyright holder for this preprint

(which was not certified by peer review) is the author/funder, who has granted bioRxiv a license to display the preprint in perpetuity. It is made available under aCC-BY 4.0 International license.

Figure 6

A
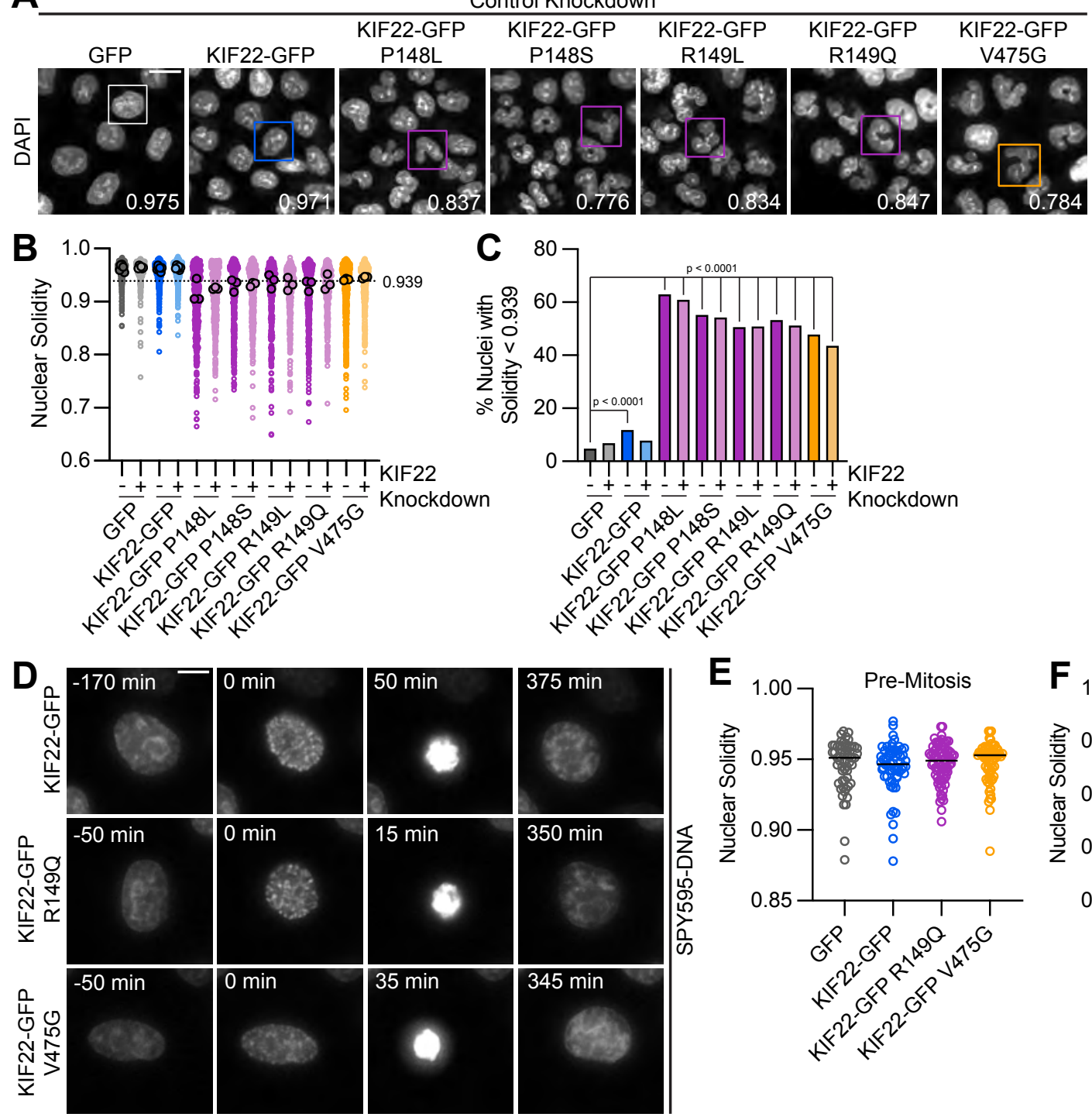

KIF22

Knockdown

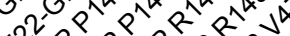

स 0 o

$2^{2} \leqslant 2^{2} \leqslant 2^{2} \leqslant 2^{2} \leqslant 2$

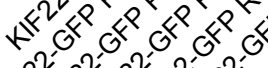

$\leqslant \leqslant 2^{2} \leqslant 2^{2} \leqslant 2^{2} \leqslant 2^{2} \leqslant 2$
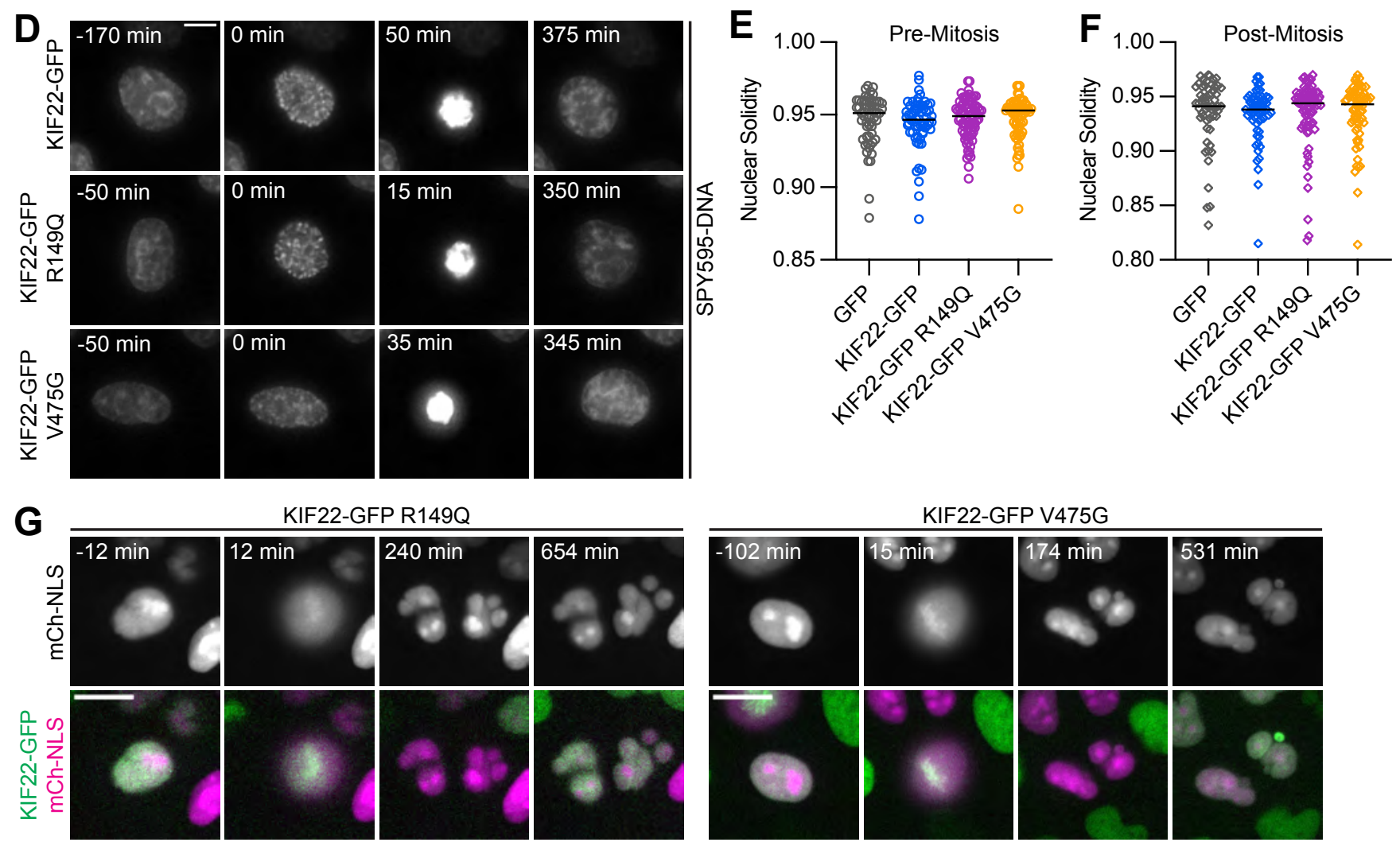
Figure 6: Division of cells expressing KIF22 with pathogenic mutations results in daughter cells with abnormally shaped nuclei.

493 (A) DAPI stained nuclei of cells expressing KIF22 with pathogenic mutations. Values in the bottom 494 right of each image indicate the solidity of the boxed nucleus. Fixed approximately 24 hours after 495 treatment with doxycycline to induce expression. Scale bar $20 \mu \mathrm{m}$. Images are representative of 4963 or more experiments. (B) Measured solidity of nuclei in HeLa-Kyoto cell lines. Small circles 497 represent the solidity of individual nuclei, and large circles with black outlines indicate the median 498 of each experiment. A dashed line marks a solidity value of 0.939 , the fifth percentile of solidity 499 for control cells transfected with control siRNA and expressing GFP. (C) Percentage of nuclei with 500 abnormal shape, indicated by a solidity value less than 0.939 , the fifth percentile of control (control 501 knockdown, GFP expression) cell solidity. A chi-square test of all data produced a $p$ value < 5020.0001 . Plotted $p$ values are from pairwise post-hoc chi-square tests comparing control (control 503 knockdown, GFP expression) cells to each other condition. Applying the Bonferroni correction for 504 multiple comparisons, a $p$ value of less than 0.00385 was considered significant. $p$ values are 505 greater than 0.00385 for comparisons without a marked $p$ value. Data in $(B)$ and $(C)$ represent 506 336-1045 cells from 3-6 experiments per condition. (D) Time-lapse images of HeLa-Kyoto cells 507 treated with nocodazole and reversine and stained with SPY595-DNA to visualize chromosomes. 508 Time indicates the number of minutes before or after chromosome condensation. Images are 509 maximum intensity projections in $z$ of two focal planes, one at the level of interphase nuclei and 510 one at the level of mitotic chromosomes. Imaged approximately 8 hours after treatment with 511 doxycycline to induce expression, 1.5-2 hours after treatment with SPY595-DNA, and 0.5-1 hour 512 after treatment with nocodazole and reversine. Scale bar $10 \mu \mathrm{m}$. Images are representative of 3 513 or more experiments. (E) Nuclear solidity of HeLa-Kyoto cells treated with nocodazole and 514 reversine. Measurements were made 15 minutes before chromosome condensation. (F) Nuclear 515 solidity of HeLa-Kyoto cells treated with nocodazole and reversine. Measurements were made 516100 minutes after chromosome decondensation. Data in (E) and (F) represent 56-76 cells from 3 517 experiments per condition. For $(E)$ and $(F)$, bars indicate medians, and the Kruskal-Wallis test 518 indicated no significant difference between groups. (G) Time-lapse images of HeLa-Kyoto cells 519 expressing mCherry ( $\mathrm{mCh}$ )-NLS to assess nuclear envelope integrity. Times indicate minutes 520 before or after chromosome condensation. Imaged approximately 8 hours after treatment with 521 doxycycline to induce expression and 24 hours after transfection with mCh-CAAX. Scale bar 20 $\mu \mathrm{m}$. Images are representative of 3 or more experiments. 
bioRxiv preprint doi: https://doi.org/10.1101/2021.09.29.462402; this version posted November 19, 2021. The copyright holder for this preprint (which was not certified by peer review) is the author/funder, who has granted bioRxiv a license to display the preprint in perpetuity. It is made available under aCC-BY 4.0 International license.

\section{Supplemental Figure 4}

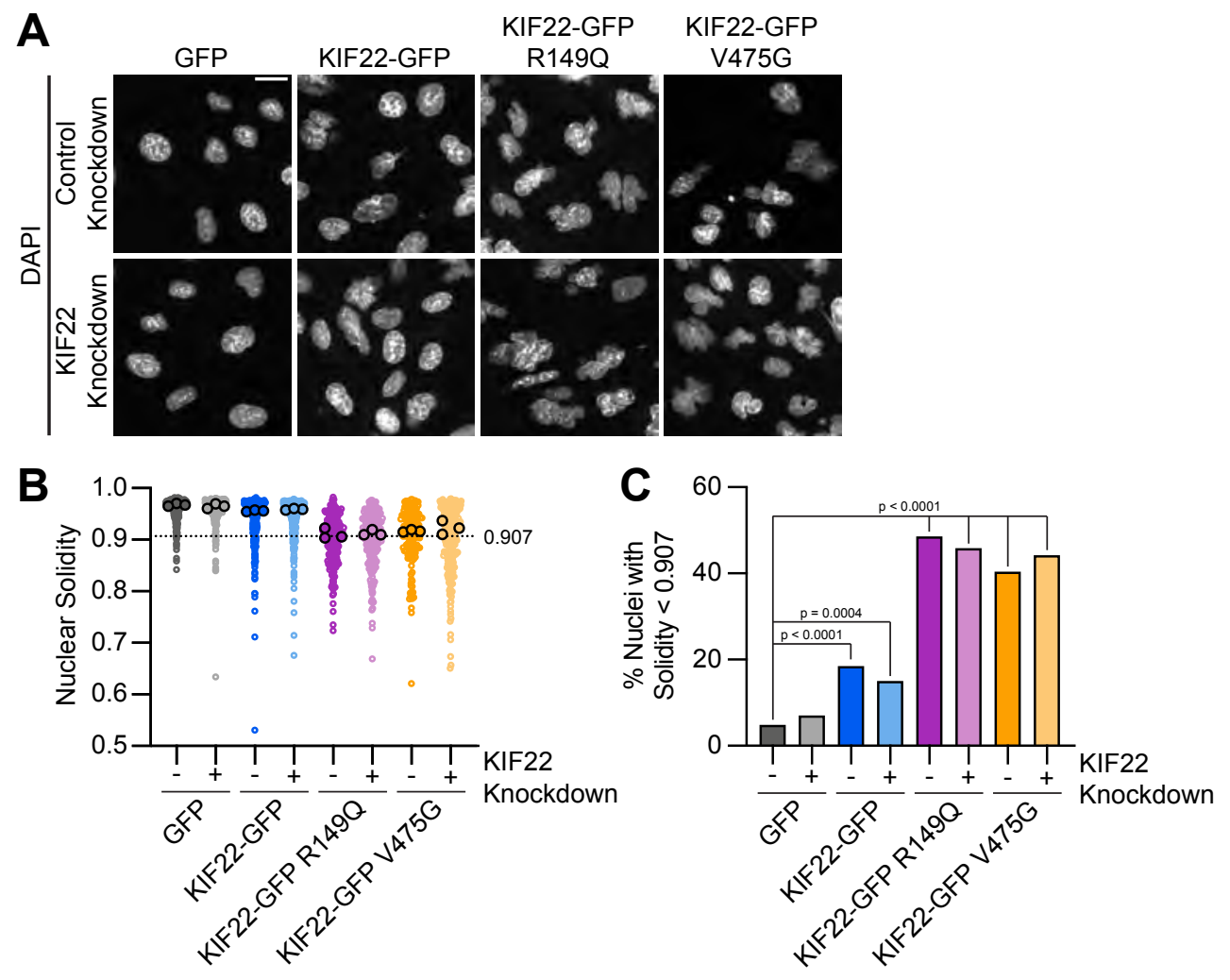




\section{Supplemental Figure 4: Mutations cause abnormally shaped nuclei in RPE1 cells.}

524 (A) DAPI-stained nuclei of RPE-1 cells expressing KIF22-GFP with pathogenic mutations. Fixed 525 approximately 24 hours after treatment with doxycycline to induce expression. Scale bar $20 \mu \mathrm{m}$. 526 Images are representative of 3 or more experiments. (B) Measured solidity of nuclei in RPE-1 cell 527 lines. Small circles represent the solidity of individual nuclei, and large circles with black outlines 528 indicate the median of each experiment. A dashed line marks a solidity value of 0.907 , the fifth 529 percentile of solidity for control cells transfected with control siRNA and expressing GFP. (C) 530 Percentage of nuclei with abnormal shape, indicated by a solidity value less than 0.907 , the fifth 531 percentile of control (control knockdown, GFP expression) cell solidity. A chi-square test of all 532 data produced a $p$ value $<0.0001$. Plotted $p$ values are from pairwise post-hoc chi-square tests 533 comparing control (control knockdown, GFP expression) cells to each other condition. Applying 534 the Bonferroni correction for multiple comparisons, a p value of less than 0.00714 was considered 535 significant. $p$ values are greater than 0.00714 for comparisons without a marked $p$ value. Data in (B) and (C) represent 146-244 cells from 3 experiments per condition. 


\section{Proliferation is reduced in cells expressing KIF22 with pathogenic mutations}

If defects in anaphase chromosome segregation and nuclear morphology affect cellular function, they may impact the ability of cells to proliferate. To test this, HeLa-Kyoto cells expressing KIF22-GFP with pathogenic mutations were imaged over 96 hours to count the numbers of cells over time (Figure 7A). The growth rates of cells expressing mutant KIF22 were reduced (Figure 7B). After 96 hours, the fold change in cell number was reduced by approximately $30 \%$ for cells expressing KIF22-GFP with pathogenic mutations (GFP control median 5.3, KIF22-GFP R149Q 3.7, KIF22-GFP V475G 3.8) (Figure 7C).

To consider what might be limiting the proliferation rate of cells expressing mutant KIF22GFP, predictions for proliferation rate based on the observed rates of nuclear morphology defects and cytokinesis failure were calculated. For these purposes, only data from the first 48 hours of the proliferation assay were used, as cell growth rates plateaued after this timepoint. The doubling time of control HeLa-Kyoto cells expressing GFP was calculated to be 20.72 hours in these experiments, which is consistent with published data (Y. Liu et al. 2018). Using this doubling rate, assuming exponential growth, and assuming every cell divides, the normalized cell count at 48 hours (normalized to a starting cell count of 1 ) was predicted to be 4.98 . This is close to the experimental 48-hour cell count for control cells (4.60), and higher than the experimental 48-hour cell count for cells expressing KIF22-GFP R149Q (3.13) or V475G (3.60), as these cell lines have reduced proliferation (Figure 7B, square). If one assumed that cells with abnormally shaped nuclei stop dividing, given that approximately $60 \%$ of mutant KIF22-GFP cell divisions result in abnormally shaped nuclei (Figure 4E), the predicted cell count at 48 hours would be 2.18 (Figure 7B, triangle). This is lower than the experimental cell count for cells expressing mutant KIF22GFP, suggesting that cells with abnormally shaped nuclei must be capable of additional divisions. If, instead, one assumed that only cells that fail cytokinesis (30\% of cells (Figure 4E)) stop dividing, the predicted cell count would be 3.42 (Figure 7B, diamond). This value is consistent with the experimental 48-hour cell count for cells expressing KIF22-GFP with pathogenic mutations $(3.13-3.60)$, suggesting the rate of cytokinesis failure may limit the rate of proliferation in these cells. Consistent with this possibility, an increased number of large cells that may have failed cytokinesis are visible in proliferation assay images at 72 hours (Figure 7A).

To test the prediction that cells with nuclear morphology defects are capable of division, 567 KIF22-GFP expression was induced approximately 24 hours before imaging to generate a 568 population of cells with abnormally shaped nuclei. Division of these cells was observed (Figure 569 7D), demonstrating that nuclear morphology defects do not prevent subsequent divisions. The 570 percentage of cells that divided over the course of this experiment was not reduced in cells 
bioRxiv preprint doi: https://doi.org/10.1101/2021.09.29.462402; this version posted November 19,2021 . The copyright holder for this preprint (which was not certified by peer review) is the author/funder, who has granted bioRxiv a license to display the preprint in perpetuity. It is made available under aCC-BY 4.0 International license.

571 expressing KIF22-GFP with pathogenic mutations despite the abnormal nuclear morphology of 572 cells in those populations (Figure 7E). 
bioRxiv preprint doi: https://doi.org/10.1101/2021.09.29.462402; this version posted November 19, 2021. The copyright holder for this preprint (which was not certified by peer review) is the author/funder, who has granted bioRxiv a license to display the preprint in perpetuity. It is made available under aCC-BY 4.0 International license.

Figure 7

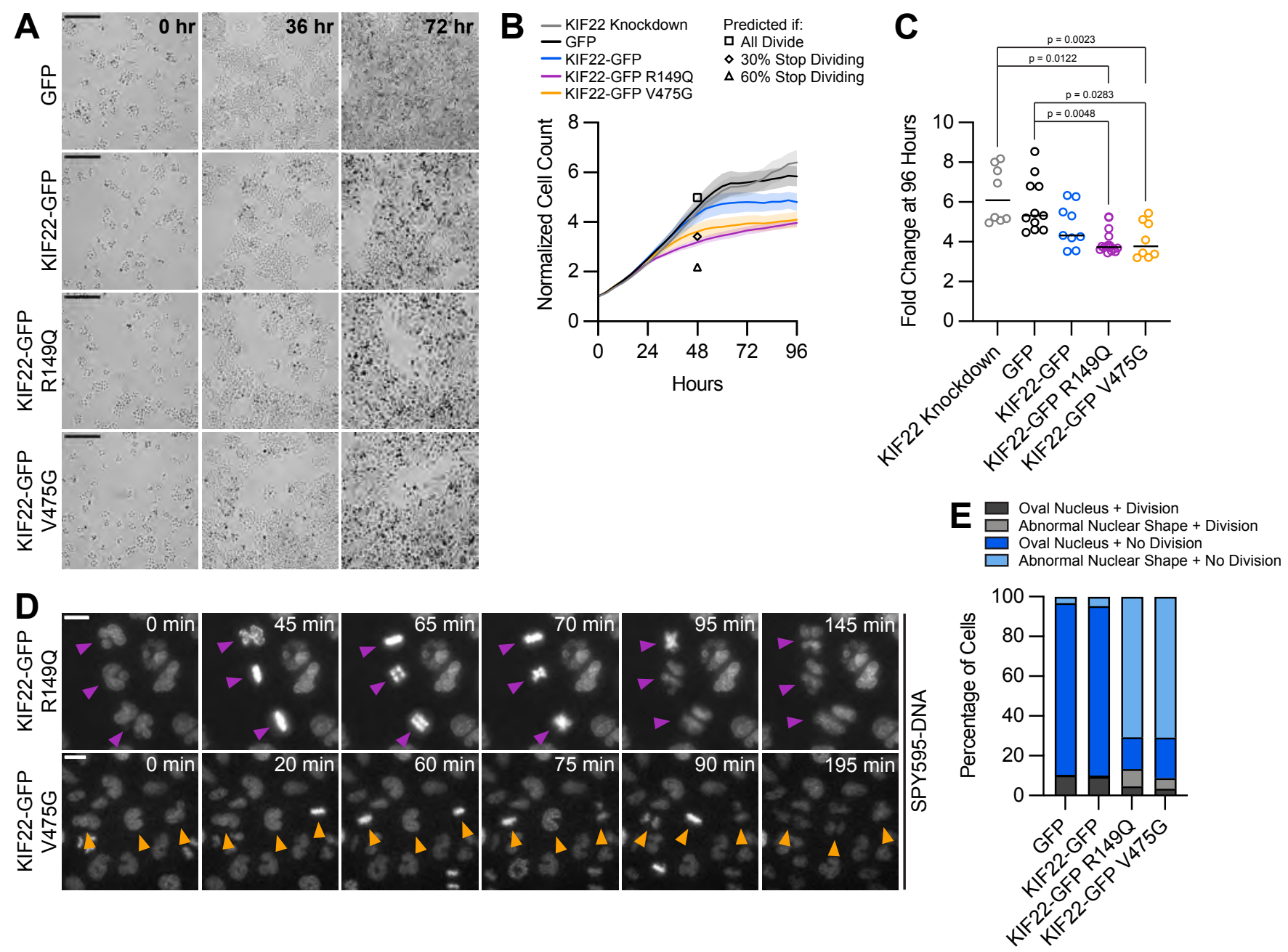


573 Figure 7: Proliferation is reduced in cells expressing KIF22 with pathogenic mutations.

574 (A) Time-lapse bright field images of HeLa-Kyoto cells to assess proliferation rate. Scale bar 500

$575 \mu \mathrm{m}$. Images are representative of 3 or more experiments. (B) Proliferation rates measured using

576 automated bright field imaging. Lines represent the mean cell count, normalized to the number of

577 cells at 0 hours, and the shaded area denotes SEM. Black outlined shapes indicate the predicted

578 cell count for cell lines expressing pathogenic mutations at 48 hours if every cell doubled every

57920.72 hours (the doubling time measured from 48 hours of control cell proliferation) (square), if

580 the rate of cytokinesis failure limited proliferation and $30 \%$ of cells did not divide (diamond), and

581 if the rate of nuclear morphology defects limited proliferation and $60 \%$ of cells did not divide

582 (triangle). (C) Fold change of normalized cell counts after 96 hours. Bars indicate medians. $p$

583 values from Kruskal-Wallis test. $p$ values are greater than 0.05 for comparisons without a marked

$584 p$ value. Data in $(B)$ and $(C)$ represent 8-16 technical replicates from 4 experiments per condition.

585 (D) Time-lapse imaging of HeLa-Kyoto cells treated with doxycycline for 24 hours to induce 586 expression of KIF22-GFP with pathogenic mutations and stained with SPY595-DNA. Arrowheads

587 indicate cells with abnormally shaped nuclei that divide. Images are maximum intensity

588 projections in $z$ of two focal planes, one at the level of interphase nuclei and one at the level of

589 mitotic chromosomes. Scale bars $20 \mu \mathrm{m}$. Images are representative of 3 or more experiments.

590 (E) Nuclear morphology at the start of imaging (dark grey or blue, oval; light grey or blue; abnormal 591 morphology) and outcome (grey, cell divides during the experiment; blue, the cell does not divide).

592 The total number of dividing cells was compared between cell lines using the chi-square test $(p<$ 5930.0001 across all conditions). Post-hoc chi-square tests comparing all conditions to one another 594 indicated that the proliferation rate of cells expressing KIF22-GFP R149Q is statistically different 595 than that of cells expressing GFP ( $p=0.0025)$, KIF22-GFP ( $p=0.0003)$, or KIF22-GFP V475G $596(p<0.0001)$. Applying the Bonferroni correction for multiple comparisons, a $p$ value of less than 5970.008 was considered significant. $p$ values are greater than 0.008 for all other comparisons. 18905982611 cells from 4 experiments per condition. 


\section{Mimicking phosphorylation of T463 phenocopies pathogenic mutations}

The phenotypes observed in cells expressing KIF22-GFP with pathogenic mutations suggest that mutations may prevent inactivation of KIF22 in anaphase, and that polar ejection

602 forces in anaphase disrupt chromosome segregation. If this is the case, then preventing KIF22 603 inactivation would be predicted to phenocopy the pathogenic mutations. One mechanism by 604 which KIF22 activity is controlled is phosphorylation of T463: phosphorylation of this tail residue 605 is necessary for polar ejection force generation, and dephosphorylation at anaphase onset 606 contributes to polar ejection force suppression (Soeda et al. 2016). Therefore, we generated 607 HeLa-Kyoto inducible cell lines expressing KIF22-GFP with phosphomimetic (T463D) and 608 phosphonull (T463A) mutations to test whether preventing KIF22 inactivation in anaphase by 609 expressing the constitutively active T463D construct phenocopies the expression of KIF22-GFP 610 with pathogenic mutations. When treated with doxycycline, these cells expressed 611 phosphomimetic and phosphonull KIF22-GFP at levels comparable to those seen in cells lines 612 expressing KIF22-GFP with pathogenic mutations, which was approximately two- to three-fold 613 higher than the level of expression of endogenous KIF22 (Figure S5A-D).

614 To assess the activity of KIF22-GFP T463D and T463A in HeLa cells, polar ejection force generation in monopolar spindles was measured (Figure 8A). In cells with endogenous KIF22 present, expression of KIF22-GFP T463D increased the distance from the spindle pole to the maximum DAPI signal (GFP control $3.7 \pm 0.07 \mu \mathrm{m}$, KIF22-GFP T463D $4.4 \pm 0.12$, mean \pm SEM), indicating increased polar ejection forces, consistent with phosphorylation of T463 activating KIF22 in prometaphase (Soeda et al. 2016) (Figure 8B). Conversely, when endogenous KIF22 was depleted, expression of KIF22-GFP T463A was less able to rescue polar ejection force generation (distance from the spindle pole to the maximum DAPI signal $3.0 \pm 0.08 \mu \mathrm{m}$, mean \pm SEM) than expression of wild type KIF22-GFP $(3.6 \pm 0.07 \mu \mathrm{m})$ or KIF22-GFP T463D $(3.7 \pm 0.10$ $\mu \mathrm{m}$ ) (Figure $\mathbf{8 C}$ ). Again, this is consistent with previous work demonstrating that KIF22 phosphorylation at T463 activates the motor for prometaphase polar ejection force generation (Soeda et al. 2016), although the reduction in polar ejection forces seen with KIF22-GFP T463A rescue is less severe in our system, possibly due to differences in cell type, level of depletion of endogenous KIF22, or the method used to quantify polar ejection forces.

In anaphase, expression of phosphomimetic KIF22-GFP T463D, but not phosphonull KIF22-GFP T463A, caused chromosome recongression (Figure 8D, 8E). The distance between 630 chromosome masses at 7 minutes was reduced in cells expressing KIF22-GFP T463D (median $6315.8 \mu \mathrm{m})$ compared to cells expressing wild type KIF22-GFP $(12.5 \mu \mathrm{m})$ or KIF22-GFP T463A (10.8 $\mu \mathrm{m})$ (Figure 8F). As in cells expressing KIF22-GFP with pathogenic mutations, the severity of 
633 anaphase chromosome recongression, indicated by the distance between chromosome masses

634 at 7 minutes, was dependent on GFP expression level (Spearman correlation coefficient -0.3964 ,

635 one-tailed $p$ value 0.0004) (Figure S5E). When only cells expressing lower levels of KIF22-GFP

636 (mean background subtracted intensity $<100$ arbitrary units) were considered, the same effect

637 (expression of KIF22-GFP T463D causes recongression) was still observed (Figure S5F, S5G).

638 This recongression phenocopies the effect of pathogenic mutations on anaphase chromosome

639 segregation, consistent with pathogenic mutations preventing anaphase inactivation of KIF22.

640 In addition to causing the same defects in anaphase chromosome segregation, expression

641 of KIF22-GFP T463D also affects daughter cell nuclear morphology. Cells expressing KIF22-GFP

642 T463D have lobed and fragmented nuclei (Figure S5H) and correspondingly reduced nuclear

643 solidity measurements (Figure 8G). An increased percentage of cells expressing KIF22-GFP

644 T463D in the presence of endogenous KIF22 (65\%) or in cells depleted of endogenous KIF22

645 (72\%) have abnormally shaped nuclei, as indicated by a solidity value below the fifth percentile

646 of control cell nuclear solidity (Figure $8 \mathrm{H}$ ).

647 Expression of KIF22-GFP T463A also resulted in a small increase in the percentage of

648 abnormally shaped nuclei (26\% in control or KIF22 knockdown conditions) (Figure $8 \mathbf{H})$. Since

649 expression of KIF22-GFP T463A does not cause anaphase recongression (Figure 8E), the level

650 of compaction of the segregating chromosome masses was explored as a possible explanation

651 for this modest increase in the percentage of cells with nuclear morphology defects. In KIF22

652 knockout mice, loss of KIF22 reduces chromosome compaction in anaphase, causing the

653 formation of multinucleated cells (Ohsugi et al. 2008). The phosphonull T463A mutation reduces

654 KIF22 activity and may therefore exhibit a KIF22 loss of function phenotype. Measurement of the

655 widths of separating chromosome masses in anaphase (Figure S5I) did demonstrate a modest

656 broadening of the chromosome masses in cells expressing KIF22-GFP T463A (Figure S5J,

657 S5K), which may contribute to the modest defects in nuclear morphology seen in these cells. 
bioRxiv preprint doi: https://doi.org/10.1101/2021.09.29.462402; this version posted November 19, 2021. The copyright holder for this preprint

(which was not certified by peer review) is the author/funder, who has granted bioRxiv a license to display the preprint in perpetuity. It is made available under aCC-BY 4.0 International license.

Figure 8
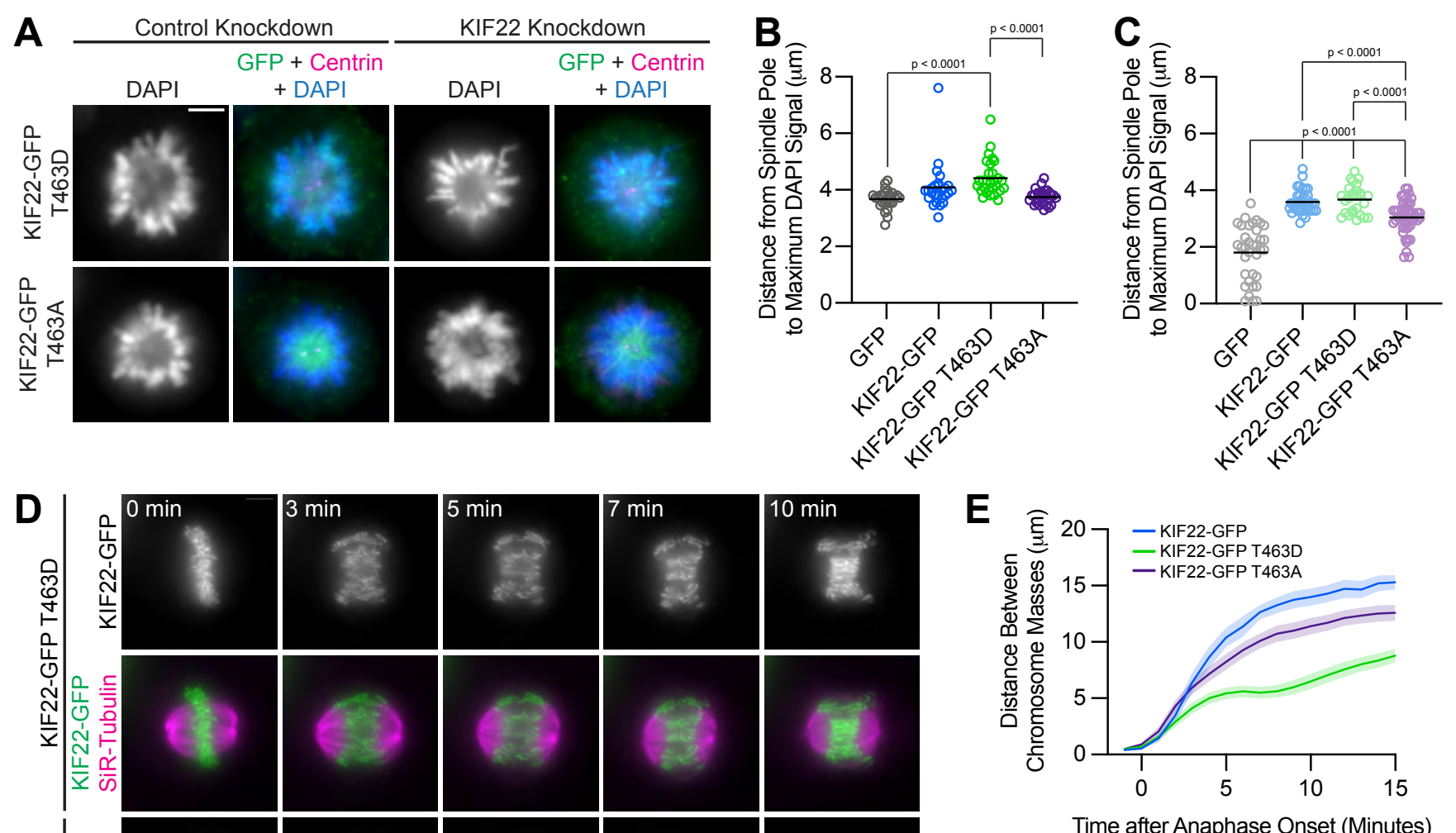

E
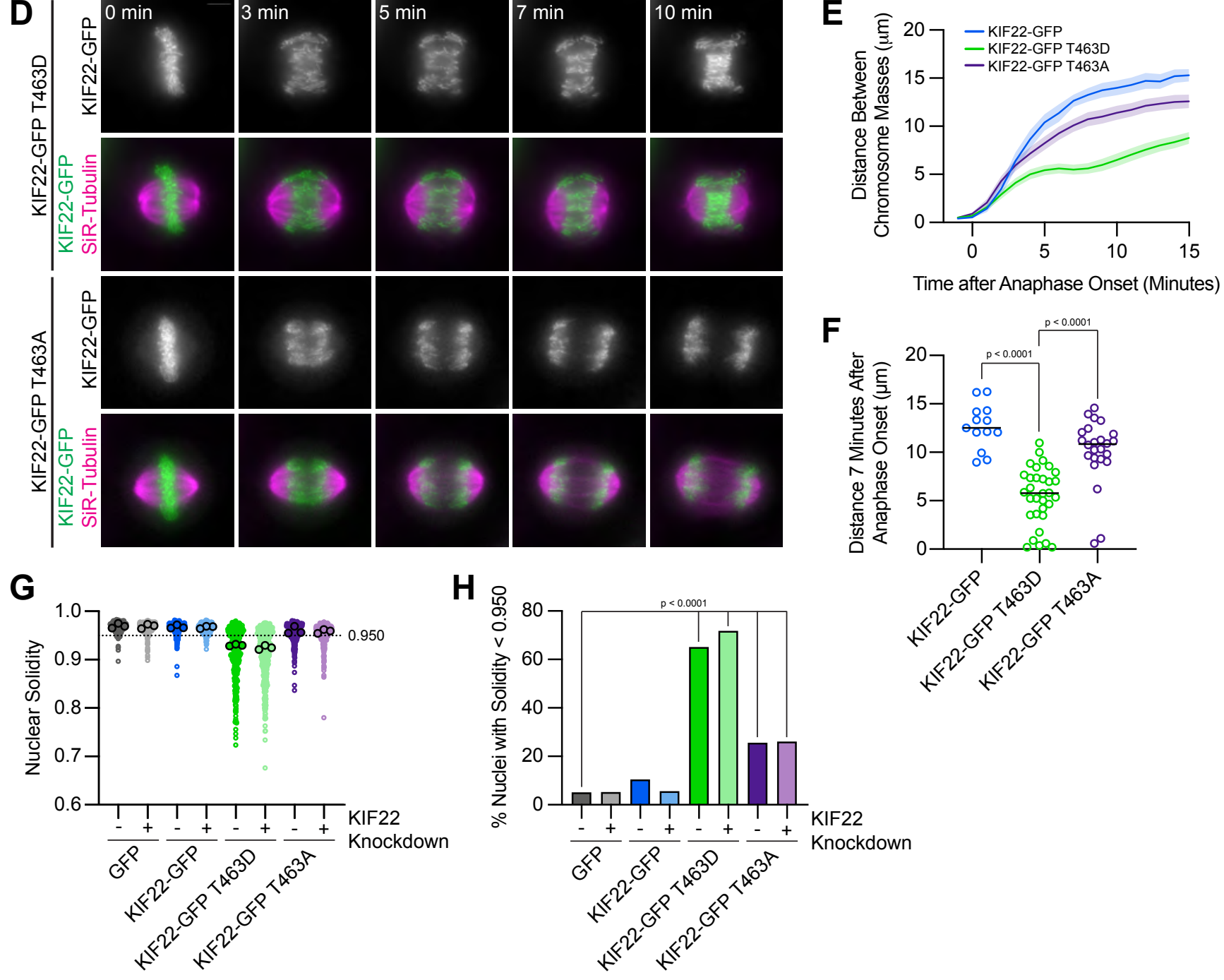
Figure 8: Phosphomimetic mutation of T463 phenocopies pathogenic mutations in KIF22.

659

660

661

662

663

664

665

666

667

668

669

670

671

672

673

674

675

676

677

678

679

680

681

682

683

684

685

686

687

688

689

(A) Immunofluorescence images of monopolar HeLa-Kyoto cells. KIF22-GFP was visualized using an anti-GFP antibody. Fixed approximately 2-3 hours after treatment with monastrol and 24 hours after siRNA transfection and treatment with doxycycline to induce expression. Scale bar 5 $\mu \mathrm{m}$. Images are representative of 3 or more experiments. (B) Distance from the spindle pole to the maximum DAPI signal, a measure of relative polar ejection force level, between HeLa-Kyoto cell lines expressing KIF22-GFP with phosphomimetic and phosphonull mutations. 26-29 cells from 3 experiments per condition. (C) Distance from the spindle pole to the maximum DAPI signal in cells depleted of endogenous KIF22 and expressing KIF22-GFP with phosphomimetic and phosphonull mutations. 27-47 cells from 3-4 experiments per condition. For B-C, bars indicate means. $p$ values from Brown-Forsythe and Welch ANOVA with Dunnett's T3 multiple comparisons test. $p$ values are greater than 0.05 for comparisons without a marked $p$ value. (D) Time-lapse images of dividing HeLa-Kyoto cells. Cells expressing KIF22-GFP T463D exhibit recongression of the chromosomes during anaphase. Times indicate minutes after anaphase onset. Images are maximum intensity projections in z through the entirety of the spindle. Imaged approximately 18 hours after treatment with doxycycline to induce expression. Scale bar $5 \mu \mathrm{m}$. Images are representative of 3 or more experiments. (E) Distance between separating chromosome masses throughout anaphase in HeLa-Kyoto cells. Lines represent the mean and the shaded area denotes SEM. 13-32 cells from 5 experiments per condition. (F) Distance between separating chromosome masses 7 minutes after anaphase onset. Bars indicate medians. $p$ values from Kruskal-Wallis test. $p$ values are greater than 0.05 for comparisons without a marked $p$ value. 1332 cells from 5 experiments per condition. (G) Measured solidity of nuclei in HeLa-Kyoto cell lines. Small circles represent the solidity of individual nuclei, and large circles with black outlines indicate the median of each experiment. A dashed line marks a solidity value of 0.950 , the fifth percentile of solidity for control cells transfected with control siRNA and expressing GFP. (H) Percentage of nuclei with abnormal shape, indicated by a solidity value less than 0.950 , the fifth percentile of control (control knockdown, GFP expression) cell solidity. A chi-square test of all data produced a $p$ value $<0.0001$. Plotted $p$ values are from pairwise post-hoc chi-square tests comparing control (control knockdown, GFP expression) cells to each other condition. Applying the Bonferroni correction for multiple comparisons, a $p$ value of less than 0.00714 was considered significant. $p$ values are greater than 0.00714 for comparisons without a marked $p$ value. Data in $(G)$ and $(H)$ represent $312-376$ cells from 3 experiments per condition. 


\section{Supplemental Figure 5}

A

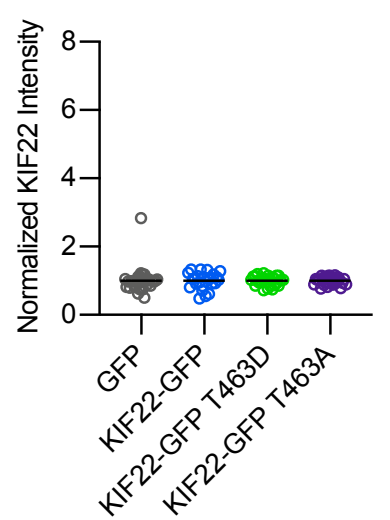

$\mathbf{E}$

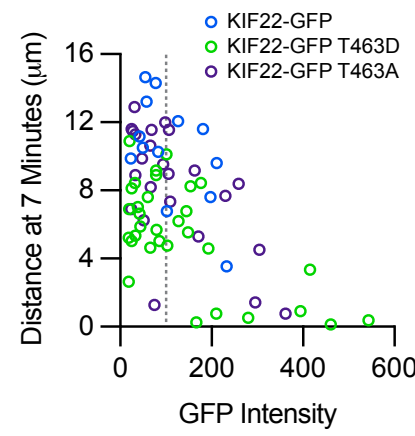

B

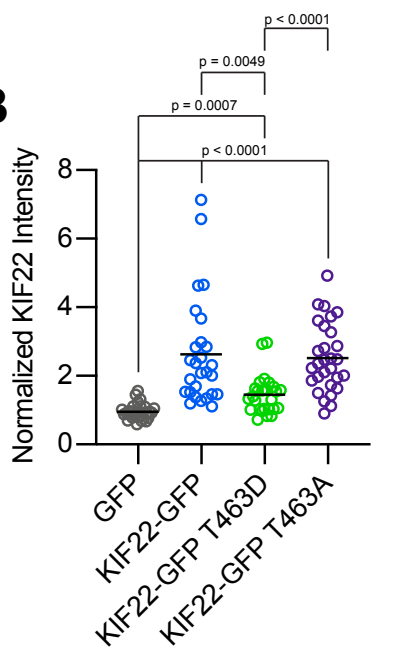

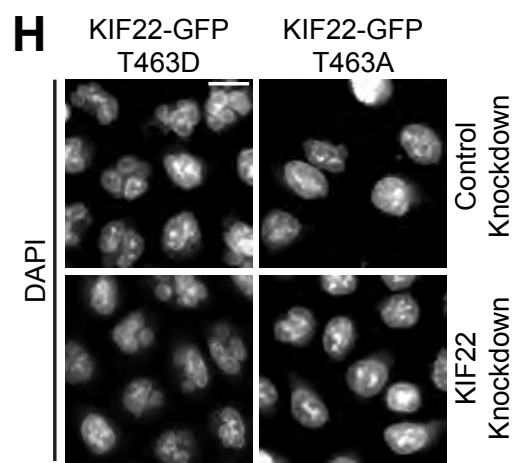

C

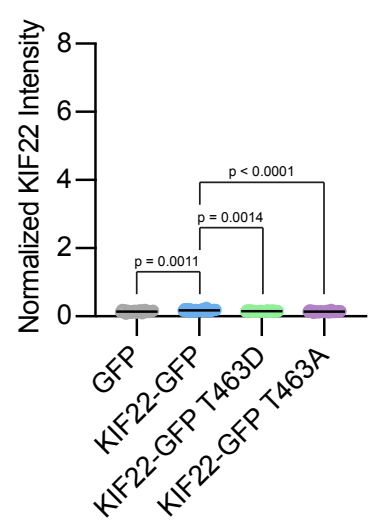

D

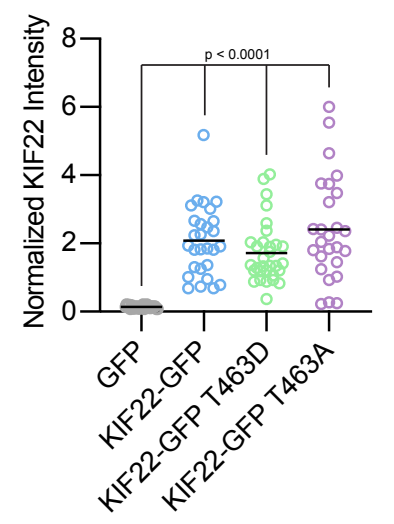

G

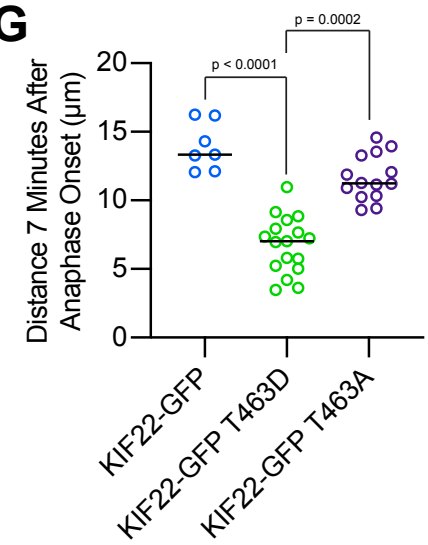

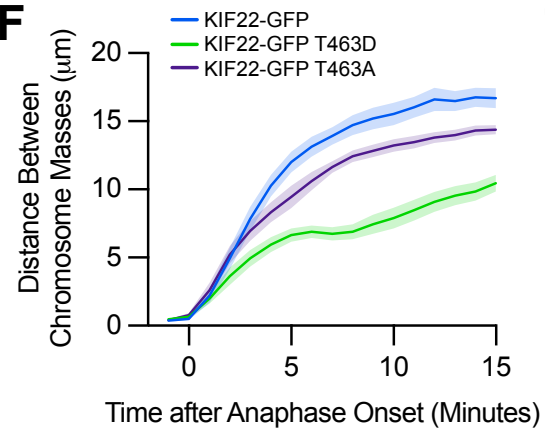

-

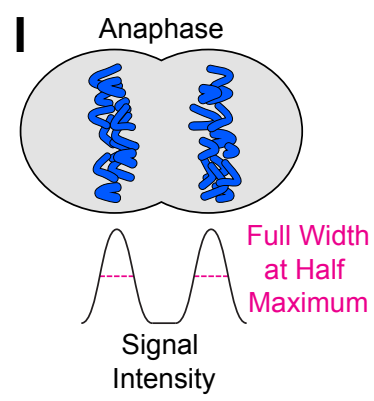

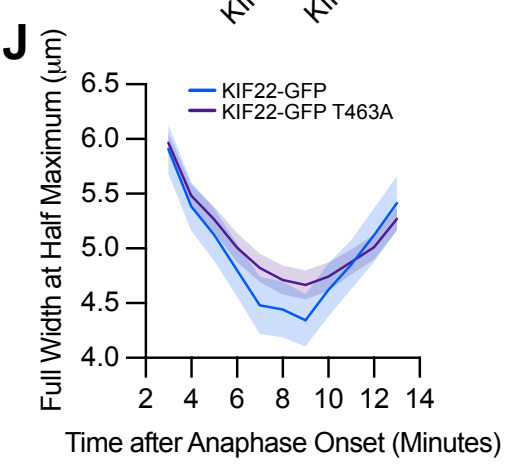

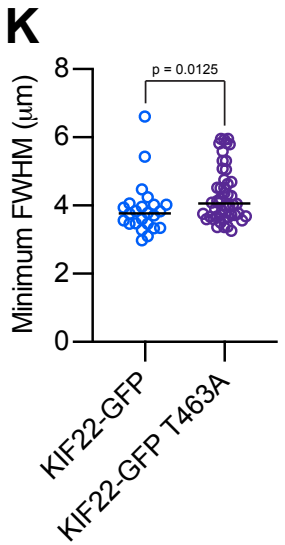


Supplemental Figure 5: Cells expressing KIF22-GFP T463A have broader anaphase 691 chromosome masses.

692 (A-D) Quantification of KIF22 fluorescence intensity in untreated HeLa-Kyoto cells transfected 693 with control siRNA (A), cells treated with doxycycline to induce expression and transfected with 694 control siRNA (B), untreated cells transfected with KIF22 siRNA (C), and cells treated with 695 doxycycline and transfected with KIF22 siRNA (D) normalized to the mean intensity of uninduced, 696 control knockdown cells (endogenous KIF22 expression level) for each cell line (A). 23-32 HeLa697 Kyoto cells per condition from 3 experiments. (E) Plotting background-subtracted GFP intensity 698 against the distance between separating chromosome masses at 7 minutes indicates that this 699 distance is dependent on expression level (Spearman correlation coefficient -0.3964, one-tailed $700 \mathrm{p}$ value $=0.0004)$. Grey dashed line indicates mean background subtracted GFP intensity of 100 . 701 13-32 cells from 5 experiments per condition. (F) Distance between separating chromosome 702 masses of cells expressing lower levels of KIF22-GFP (mean background subtracted GFP 703 intensity less than 100). Lines represent the mean and the shaded area denotes SEM. 7-14 cells 704 from 4-5 experiments per condition. (G) Distance between separating chromosome masses 7 705 minutes after anaphase onset of cells expressing lower levels of KIF22-GFP (mean background 706 subtracted GFP intensity less than 100). Bars indicate medians. p values from Kruskal-Wallis test. $707 \mathrm{p}$ values are greater than 0.05 for comparisons without a marked $p$ value. 7-14 cells from 4-5 708 experiments per condition. (H) DAPI-stained nuclei of Hela-Kyoto cells. Fixed approximately 24 709 hours after treatment with doxycycline to induce expression. Scale bar $20 \mu \mathrm{m}$. Images are 710 representative of 3 or more experiments. (I) Schematic depicting the measurement of 711 chromosome signal intensity in anaphase and the use of the full width at half maximum (FWHM) 712 as a measure of anaphase chromosome mass broadness. (J) Full width at half maximum of the 713 plotted intensities of separating chromosome masses of HeLa-Kyoto cells expressing KIF22-GFP 714 or KIF22-GFP T463A. Lines represent the mean and the shaded area denotes SEM. (K) Minimum 715 FWHM value, representing maximal anaphase chromosome compaction, between cells 716 expressing KIF22-GFP and KIF22-GFP T463A. $p$ value from Mann-Whitney test. Bars represent 717 medians. Data in $(\mathrm{J})$ and $(\mathrm{K})$ represent $24-48$ cells from 5 experiments per condition. 
bioRxiv preprint doi: https://doi.org/10.1101/2021.09.29.462402; this version posted November 19, 2021. The copyright holder for this preprint (which was not certified by peer review) is the author/funder, who has granted bioRxiv a license to display the preprint in perpetuity. It is made available under aCC-BY 4.0 International license.

\section{Figure 9}

A

Wild type

KIF22

B

KIF22 with pathogenic mutations

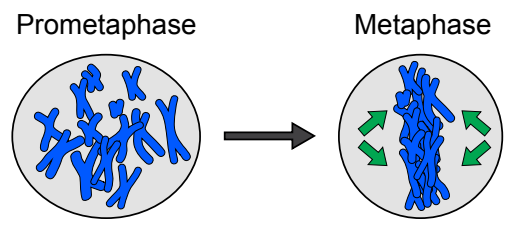

Polar ejection force generation

Polar ejection force generation

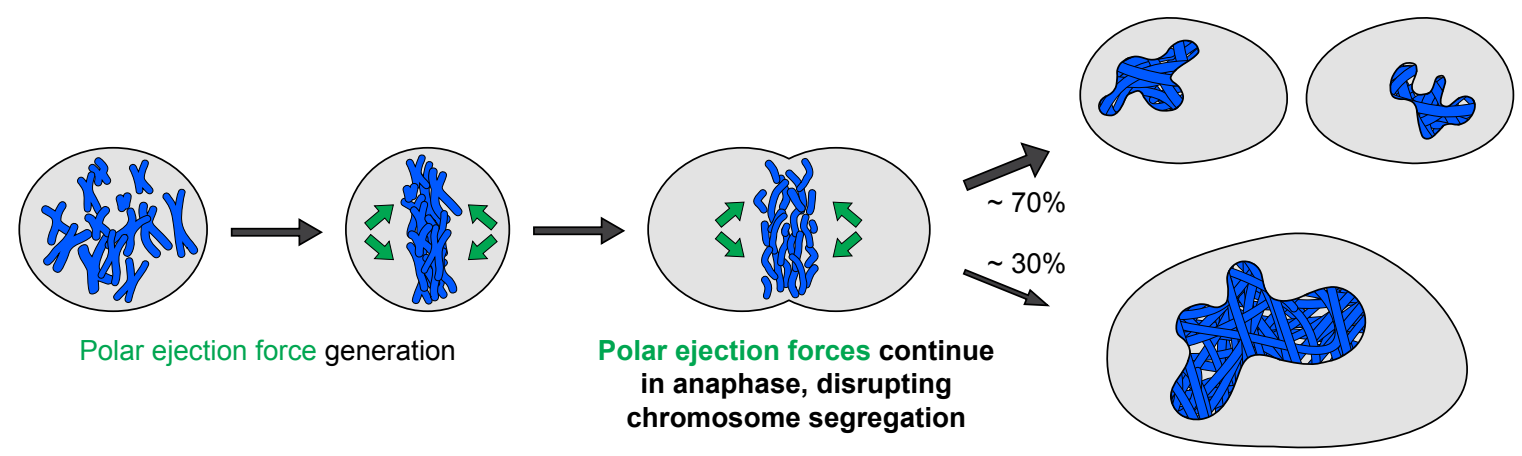

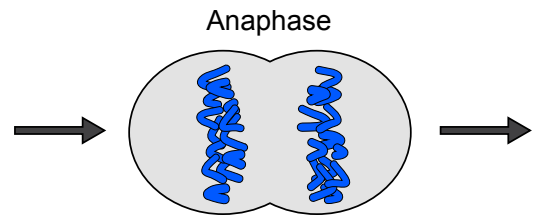

Polar ejection forces attenuated in anaphase

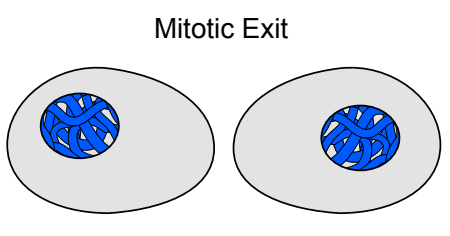

No defects

Cytokinesis failure, defects in nuclear morphology, and reduced proliferation 


\section{Figure 9. Pathogenic mutations disrupt the anaphase, but not prometaphase, function of}

\section{KIF22.}

720 (A) Wild type KIF22 generates polar ejection forces to contribute to chromosome congression 721 and alignment in prometaphase. In anaphase, KIF22 inactivation results in the attenuation of polar 722 ejection forces (green arrows), allowing chromosomes to segregate toward the poles. Daughter 723 cells form regularly shaped nuclei and continue to proliferate. (B) In cells expressing KIF22 with 724 pathogenic (P148L, P148S, R149L, R149Q, V475G) or phosphomimetic (T463D) mutations, 725 prometaphase proceeds as in cells expressing wild type motor. Mutant KIF22 is capable of polar 726 ejection force generation. In anaphase, KIF22 fails to inactivate, resulting in continued generation 727 of polar ejection forces, which disrupts anaphase chromosome segregation. Daughter cells exhibit 728 nuclear morphology defects. In about $30 \%$ of cells, cytokinesis fails, and proliferation rates are reduced. 


\section{DISCUSSION}

We have determined that pathogenic mutations in KIF22 disrupt anaphase chromosome segregation, causing chromosome recongression, nuclear morphology defects, reduced proliferation, and, in a subset of cells, cytokinesis failure. Wild type KIF22 is inactivated in anaphase (Soeda et al. 2016), resulting in an attenuation of polar ejection forces, which allows chromosomes to move towards the spindle poles (Figure 9A). The phenotypes we observe in cells expressing KIF22-GFP with pathogenic mutations are consistent with KIF22 remaining active in anaphase (Figure 9B). Polar ejection forces could cause recongression by continuing to push chromosomes away from the spindle poles during anaphase. These forces would result in aberrant positioning of chromosomes during telophase and cytokinesis, which could cause the nuclear morphology defects and cytokinesis failure we observe in cells expressing mutant KIF22GFP. Consistent with this model, mimicking phosphorylation of T463 to prevent KIF22 inactivation in anaphase phenocopies the effects of pathogenic mutations. Thus, we conclude that pathogenic mutations result in a gain of KIF22 function, which aligns with findings that KIF22 mutations are dominant in heterozygous patients (Min et al. 2011; Boyden et al. 2011; Tüysüz et al. 2014). The effects of pathogenic mutations on chromosome movements in anaphase are consistent with observations of chromosome recongression in cells with altered CDK1 activity (Wolf et al. 2006; Su et al. 2016) or altered tail structure (Soeda et al. 2016). Our work additionally demonstrates proliferation.

Mutations in both the motor domain (P148L, P148S, R149L, and R149Q) and the coiledcoil domain (V475G) of KIF22 disrupt chromosome segregation in a manner consistent with a failure of KIF22 inactivation in anaphase. This finding could contribute to our understanding of the mechanism by which KIF22 is inactivated, adding to studies that demonstrate that deletion of the tail microtubule binding domain and deletion or disruption of the coiled-coil domain also prevents the inactivation of KIF22 in anaphase (Soeda et al. 2016). Given that mutations in the tail and motor domain of KIF22 both disrupt chromosome segregation, the tail and motor domain may interact to inactivate the motor. Head-tail autoinhibition is a known regulatory mechanism of other members of the kinesin superfamily (Verhey et al. 1998; Coy et al. 1999; Friedman and Vale 1999; Imanishi et al. 2006; Espeut et al. 2008; Hammond et al. 2009; Hammond et al. 2010; Ren et al. 2018; Blasius et al. 2021; Verhey and Hammond 2009), and disruption of autoinhibition can

761 be a mechanism of disease pathogenesis (van der Vaart et al. 2013; Cheng et al. 2014; Bianchi 762 et al. 2016; Asselin et al. 2020; Blasius et al. 2021). Mutations in either the tail or motor domain could disrupt this interaction, preventing KIF22 inactivation in anaphase. As amino acids P148, 
R149, and V475 are highly conserved across species in members of the kinesin-10 family (Figure 1C), this inactivation mechanism may be present in these motors as well.

Alternatively, it has been proposed that the tail of KIF22 may interact with microtubules to suspend polar ejection force generation (Soeda et al. 2016). In this framework, the mutation in the tail of KIF22 (V745G) could disrupt anaphase chromosome segregation by altering this interaction with microtubules. Motor domain mutations would not be expected to alter the interaction of the tail with the surface of microtubules, and in this model would cause the same cellular phenotype by altering KIF22 inactivation via a different mechanism, potentially related to the mechanochemical cycle of the motor given the location of these mutations in the $\alpha 2$ helix. An additional alternative model for how pathogenic mutations affect the inactivation of KIF22 in anaphase could be that mutations alter phosphoregulation of KIF22 activity. If mutations prevented the dephosphorylation of T463 in anaphase this could cause anaphase recongression. However, addition of a phosphonull T463A mutation to KIF22 with coiled-coil or microtubule binding domain deletions does not rescue anaphase chromosome recongression defects (Soeda et al. 2016), suggesting that the role of the KIF22 tail in motor inactivation is not only to facilitate dephosphorylation of T463.

While chromosomes in some cells, particularly those expressing KIF22-GFP at high levels, completely failed to segregate and decondensed in the center of the spindle, most cells demonstrated chromosome recongression wherein poleward motion of chromosomes begins, but then chromosomes switch direction and move anti-poleward. These dynamics may be due to differences in microtubule density closer to the poles compared to the center of the spindle. This model is consistent with work demonstrating that in monopolar spindles, poleward movement of chromosomes is limited by chromosomes reaching a threshold density of microtubules at which polar ejection forces are sufficient to cause chromosomes to switch to anti-poleward movement (Cassimeris et al. 1994). We observed that chromosomes on the periphery of the spindle remain closer to the poles while central chromosomes are pushed further away from the poles during recongression in cells expressing KIF22-GFP with pathogenic mutations. This could also be explained by the central chromosomes encountering a higher density of microtubules, and KIF22 bound to these chromosomes therefore generating higher levels of polar ejection forces. In 793 addition, this mechanism is consistent with observations that oscillations of peripheral 794 chromosomes are reduced compared to chromosomes at the center of the spindle (Cimini et al. 795 2004; Cameron et al. 2006; Stumpff et al. 2008; Civelekoglu-Scholey et al. 2013), which could 
796

797

798

799

800

801

802

803

804

805

806

807

808

809

810

811

812

813

814

815

816

817

818

819

820

821

822

823

824

825

826

827

828

829 also be explained by reduced peripheral microtubule density limiting peripheral polar ejection force generation.

Our assessment of the relative trajectories of chromosomes, centromeres, and spindle poles offers insight into the relative magnitudes of polar ejection forces and other anaphase forces. Expression of KIF22-GFP with pathogenic mutations did not alter the distance between centromeres and spindle poles, indicating that while anaphase polar ejection forces altered the position of chromosome arms within the spindle, these forces were not sufficient to prevent the shortening of k-fibers. However, the expression of mutant KIF22-GFP does also alter the movements of the spindle poles, allowing assessment of the relative magnitude of polar ejection forces compared to the forces generated by the sliding of antiparallel spindle microtubules to separate the spindle poles in anaphase (Sawin et al. 1992; Nislow et al. 1992; Straight et al. 1998; Brust-Mascher et al. 2004; Tanenbaum et al. 2009; Fu et al. 2009; van Heesbeen et al. 2014; Vukušić et al. 2021; Vukušić et al. 2019). In cells expressing mutant KIF22-GFP, spindle pole separation stalled, and poles moved closer to one another during anaphase chromosome recongression. This suggests that the polar ejection forces collectively generated by mutant KIF22 motors are of greater magnitude than the forces sliding the spindle poles apart during anaphase B. Although it is important to note that this phenotype was observed with moderate overexpression of mutant KIF22, the observed effects on spindle pole separation underscore the importance of KIF22 inactivation, and imply that reducing polar ejection forces is required for both anaphase $A$ and anaphase $B$. This force balance may differ between cell types, as tail domain deletions that alter chromosome movements do not disrupt anaphase $B$ in mouse oocyte meiosis (Soeda et al. 2016).

Patients with mutations in KIF22 exhibit defects in skeletal development. The pathology observed in the patient heterozygous for the V475G mutation differs from those seen in SEMDJL2 patients with motor domain mutations (Figure 1E, 1F) (Min et al. 2011; Boyden et al. 2011; Tüysüz et al. 2014). However, a meaningful comparison of pathologies between patients is limited both by the fact that only a single patient with a mutation in the tail of KIF22 has been identified, and by the considerable variation in clinical presentation between patients with motor domain mutations, even between patients with the same point mutation (Min et al. 2011; Boyden et al. 2011; Tüysüz et al. 2014). The defects in chromosome segregation we observed in cells expressing mutant KIF22-GFP may contribute to skeletal developmental pathogenesis. Mutations could cause reduced proliferation of growth plate chondrocytes, which in turn could limit bone growth. Disrupting cytokinesis in the growth plate causes shorter bones and stature in mice (Gan et al. 2019), and mutations in KIF22 could affect development via this mechanism. The presence 
830 of pathologies in other cartilaginous tissues, including the larynx and trachea, in patients with

831 mutations in the motor domain of KIF22 (Boyden et al. 2011) is also consistent with a disease

832 etiology based in aberrant chondrocyte proliferation. Defects in mitosis could result in tissue-

833 specific patient pathology based on differences in force balance within anaphase spindles in

834 different cell types arising from different expression or activity levels of mitotic force generators or

835 regulators. Growth plate chondrocytes, particularly, are organized into columns and must divide

836 under geometric constraints (Dodds 1930), which could increase sensitivity to anaphase force

837 imbalances. Additionally, we cannot exclude the possibility that these mutations may affect the

838 function of interphase cells, which could affect development via a mechanism independent from

839 the effects of the mutations on mitosis. Future work will be required to distinguish among these

840 possible explanations.

MATERIALS AND METHODS

Patient assessment

Clinical exome sequencing was performed by the Department of Laboratory Medicine and Pathology at Mayo Clinic in Rochester, Minnesota, USA as previously described (Cousin et al. 2019). Carbohydrate deficient transferrin testing for congenital disorders of glycosylation was performed at Mayo Clinic Laboratories, Rochester, Minnesota, USA (Lefeber et al. 2011).

\section{Cell culture}

HeLa-Kyoto and RPE-1 cell lines were grown in Minimum Essential Media $\alpha$ (Gibco \#12561-056) supplemented with 10\% fetal bovine serum (Gibco \#16000-044) at 37 $\mathrm{C}$ with 5\%

$852 \mathrm{CO}_{2}$. Cell lines were validated by short tandem repeat (STR) DNA typing using the Promega 853 GenePrint 10 System according to the manufacturer's instructions (Promega \#B9510). Cells were 854 cryopreserved in Recovery Cell Culture Freezing Medium (Gibco \#12648-010). HeLa-Kyoto and 855 RPE-1 acceptor cell lines for recombination (both gifts from Ryoma Ohi, University of Michigan) were maintained in media supplemented with $10 \mu \mathrm{g} / \mathrm{mL}$ blasticidin (Thermo Fisher Scientific \#R21001).

\section{Transfection}

siRNA transfection was performed using Lipofectamine RNAiMax Transfection Reagent (Thermo Fisher Scientific \#13778150) in Opti-MEM Reduced Serum Media (Gibco \#31985-062). 
with Silencer Negative Control siRNA \#2 (Ambion \#AM4613). DNA transfections were performed using Lipofectamine LTX (Thermo Fisher Scientific \#15338100) in Opti-MEM Reduced Serum Media (Gibco \#31985-062).

\section{Plasmids}

Plasmids related to the generation of inducible cell lines are described in Table 1. A Cterminally tagged KIF22-GFP plasmid was constructed by adding EcoRI and Kpnl sites to the 871 KIF22 open reading frame (from pJS2161 (Stumpff et al. 2012)), performing a restriction digest, 872 and ligating the products into a digested pEGFP-N2 vector (Clontech) (pAT4206). Site-directed 873 mutagenesis was performed to add silent mutations for siRNA resistance (pAT4226). The open 874 reading frame from pAT4226 and the pEM791 vector (Khandelia et al. 2011) were amplified and 875 combined using Gibson Assembly (New England BioLabs) to generate a plasmid for 876 recombination-mediated construction of inducible cell lines (pAT4250). Site-directed mutagenesis 877 was performed on pAT4250 to generate plasmids encoding KIF22-GFP P148L, P148S, R149L, R149Q, V475G, T463D, and T463A for recombination. See Table 1 for primer sequences.

The mCh-CAAX plasmid was a gift from Alan Howe (University of Vermont). The mChNLS plasmid was generated by Michael Davidson and obtained from Addgene (mCh-Nucleus-7, \#55110). The pericentrin-RFP plasmid (Gillingham and Munro 2000) was a gift from Sean Munro (MRC Laboratory of Molecular Biology). The CENPB-mCh plasmid (D. Liu et al. 2010) was generated by Michael Lampson and obtained from Addgene (\#45219).

\section{Generation of inducible cell lines}

Inducible cell lines were generated using recombination-mediated cassette exchange as previously described (Khandelia et al. 2011). Briefly, plasmids (see Table 1) encoding siRNAresistant KIF22-GFP constructs were cotransfected with a plasmid encoding nuclear localized Cre recombinase (pEM784) into HeLa-Kyoto (Sturgill et al. 2016) or RPE-1 acceptor cells using Lipofectamine LTX transfection (Thermo Fisher Scientific \#15338100). For HeLa-Kyoto cell lines, 24 hours after transfection cells were treated with $1 \mu \mathrm{g} / \mathrm{mL}$ puromycin (Thermo Fisher Scientific \#A11139-03) for 48 hours, then $2 \mu \mathrm{g} / \mathrm{mL}$ puromycin for 48 hours for more stringent selection, and finally $1 \mu \mathrm{g} / \mathrm{mL}$ puromycin until puromycin-sensitive cells were eliminated. Selection of RPE-1 cells was accomplished via treatment with $5 \mu \mathrm{g} / \mathrm{mL}$ puromycin for 48 hours beginning 24 hours after transfection, then $10 \mu \mathrm{g} / \mathrm{mL}$ puromycin for 48 hours, and finally $5 \mu \mathrm{g} / \mathrm{mL}$ puromycin until puromycin-sensitive cells were eliminated. Inducible cell lines were maintained in puromycin 
inserted DNA in the selected cell populations, genomic DNA was extracted using the QIAmp DNA Blood Mini Kit (Qiagen \#51106) and subjected to sequencing (Eurofins). Expression of inserted DNA sequences was induced via treatment with $2 \mu \mathrm{g} / \mathrm{mL}$ doxycycline (Thermo Fisher Scientific \#BP26531).

\section{Immunofluorescence}

For fixed cell imaging, cells were grown on $12 \mathrm{~mm}$ glass coverslips in 24-well plates. Cells were fixed in $1 \%$ paraformaldehyde in ice-cold methanol for 10 minutes on ice. Cells were blocked for 1 hour using 20\% goat serum (Gibco \#16210-064) in antibody dilution buffer (AbDil, 1\% bovine serum albumin (Sigma Aldrich \#B4287), 0.1\% Triton X-100 (Sigma Aldrich \#93443), 0.02\% sodium azide (Fisher Scientific \#BP9221) in TBS) and incubated with the following primary antibodies for one hour at room temperature: mouse anti- $\alpha$-tubulin (DM1 $\alpha$ ) 1:500 (Millipore Sigma \#T6199), rat anti-tubulin clone YL1/2 1:1500 (Millipore Sigma \#MAB1864), rabbit anti-KIF22 1:500 (GeneTex \#GTX112357), mouse anti-centrin 1:500 (Millipore Sigma \#04-1624), or rabbit antiGFP 1:1000 (Invitrogen \#A11121). Cells were incubated with secondary antibodies conjugated to AlexaFluor 488, 594, or 647 (Invitrogen Molecular Probes \#A11034, A11037, A21245, A11029, A11032, A21236, A11007) for one hour at room temperature. Coverslips were mounted on slides using Prolong Gold mounting medium with DAPI (Invitrogen Molecular Probes \#P36935).

\section{Microscopy}

Images were acquired using a Nikon Ti-E or Ti-2E inverted microscope driven by NIS Elements software (Nikon Instruments). Images were captured using a Clara cooled chargecoupled device (CCD) camera (Andor) or Prime BSI scientific complementary metal-oxidesemiconductor (sCMOS) camera (Teledyne Photometrics) with a Spectra-X light engine (Lumencore). Samples were imaged using Nikon objectives Plan Apo 40X 0.95 numerical aperture (NA), Plan Apo $\lambda$ 60X 1.42 NA, and APO 100X 1.49 NA. For live imaging, cells were imaged in $\mathrm{CO}_{2}$-independent media (Gibco \#18045-088) supplemented with $10 \%$ fetal bovine serum (Gibco \#16000-044) in a $37^{\circ} \mathrm{C}$ environmental chamber. Images were processed and analyzed using Image J/FIJI (Schneider et al. 2012; Schindelin et al. 2012).

\section{KIF22-GFP expression level quantitation}

HeLa-Kyoto or RPE-1 cells were treated with $2 \mu \mathrm{g} / \mathrm{mL}$ doxycycline to induce expression and transfected with control or KIF22 siRNA approximately 24 hours prior to fixation. Metaphase 
932 immunofluorescence intensity were made in a background region of interest (ROI) containing no

933 cells and an ROI representing the chromosomes, identified by thresholding DAPI signal. The

934 mean background subtracted KIF22 signal on the chromosomes was calculated by subtracting

935 the product of the mean background intensity and the chromosome ROI area from the

936 chromosome ROI integrated density and dividing by the area of the chromosome ROI. KIF22

937 intensities were normalized to the mean KIF22 intensity in control cells (control knockdown,

938 uninduced) in each experimental replicate.

939

\section{Metaphase chromosome spreads}

RPE-1 cells were grown in $60 \mathrm{~mm}$ dishes for approximately 24 hours. Media was exchanged to fresh growth media for 2 hours to promote mitosis. Cells were arrested in 0.02 $\mu \mathrm{g} / \mathrm{mL}$ colcemid (Gibco KaryoMAX\#15212012) for three hours at $37^{\circ} \mathrm{C}$, then trypsinized, pelleted, and gently re-suspended in $500 \mu \mathrm{L}$ media. $5 \mathrm{~mL} 0.56 \% \mathrm{KCl}$ hypotonic solution was added dropwise to the cell suspension, which was then incubated for 15 minutes in a $37^{\circ} \mathrm{C}$ water bath. Cells were pelleted, gently resuspended, and fixed via the addition of $1 \mathrm{~mL}$ ice-cold $3: 1$ methanol:glacial acetic acid. Cells were pelleted and resuspended in fixative an additional three times, then stored at $-20^{\circ} \mathrm{C}$. Metaphase chromosome spreads were prepared by humidifying the surface of glass slides by exposing them to the steam above a $50^{\circ} \mathrm{C}$ water bath, placing the slides at an angle relative to the work surface, and dropping approximately $100 \mu \mathrm{L}$ of ice-cold cell suspension onto the slide from a height of approximately one foot. Slides were dried on a hot plate, then covered with Prolong Gold mounting medium with DAPI (Invitrogen Molecular Probes \#P36935) and sealed.

\section{Fluorescence recovery after photobleaching}

HeLa-Kyoto cells were seeded in glass-bottom 35 mm dishes (Greiner Bio-One \#627975 and \#627965) and treated with $2 \mu \mathrm{g} / \mathrm{mL}$ doxycycline to induce expression 18-24 hours before imaging. Cells were imaged at 5 second intervals for 25 seconds before bleaching, photobleached using a point-focused $405 \mathrm{~nm}$ laser, and imaged at 20 second intervals for 10 minutes after bleaching. Fluorescence intensities in bleached, unbleached, and background regions of each frame were measured using a circular ROI, area $0.865 \mu \mathrm{m}^{2}$. For interphase and metaphase cells, unbleached measurements were made on the opposite side of the nucleus or chromosome mass as the bleached measurements. For anaphase cells, one segregating chromosome mass was bleached, and unbleached measurements were made on the opposite chromosome mass. 
Background intensities, measured in cell-free area, were subtracted from bleached and unbleached intensities. Background-subtracted intensities were normalized to the intensity of the first frame imaged.

\section{Polar ejection force assay}

HeLa-Kyoto cells were treated with $2 \mu \mathrm{g} / \mathrm{mL}$ doxycycline to induce expression and transfected with control or KIF22 siRNA approximately 24 hours prior to fixation. Cells were arrested in $100 \mu \mathrm{M}$ monastrol (Selleckchem \#S8439) for 2-3 hours before fixation. Monopolar mitotic cells oriented perpendicular to the coverslip were imaged at the focal plane of the spindle pole for polar ejection force measurements. A circular ROI with a $12.5 \mu \mathrm{m}$ radius was centered around the spindle pole of each cell, and the radial profile of DAPI signal intensity at distances from the pole was measured (Radial Profile Plot plugin, https://imagej.nih.gov/ij/plugins/radialprofile.html). The distance from the pole to the maximum DAPI signal was calculated for each cell as a measure of relative polar ejection forces.

\section{Analyses of anaphase chromosome segregation}

HeLa-Kyoto or RPE-1 cells were treated with $2 \mu \mathrm{g} / \mathrm{mL}$ doxycycline to induce expression approximately 18 hours before imaging. For HeLa-Kyoto cells, media was exchanged to $\mathrm{CO}_{2}$ indpendent media containing $2 \mu \mathrm{g} / \mathrm{mL}$ doxycycline and $100 \mathrm{nM}$ SiR-Tubulin (Spirochrome \#SC002) approximately 1-1.5 hours before imaging. For RPE-1 cells, media was exchanged to $\mathrm{CO}_{2}$-indpendent media containing $2 \mu \mathrm{g} / \mathrm{mL}$ doxycycline, 20-100 nM SiR-Tubulin (Spirochrome \#SC002), and $10 \mu \mathrm{M}$ verapamil (Spirochrome \#SCV01) approximately 1.5-3 hours before imaging. Cells were imaged at 1 minute time intervals. Distances between segregating chromosome masses were measured by plotting the KIF22-GFP signal intensity along a line drawn through both spindle poles (macro available at https://github.com/StumpffLab/ImageAnalysis). This data set was split at the center distance to generate two plots, each representing one half-spindle/segregating chromosome mass. The distance between the maximum of each intensity plot was calculated using MATLAB (Mathworks, Version R2018a) (script available at https://github.com/StumpffLab/lmage-Analysis). To assess the broadness of segregating chromosome masses in cells expressing KIF22-GFP T463A, a Gaussian curve was fit to the same intensity plots and the full width at half maximum was calculated in MATLAB.

To measure the movements of spindle poles and kinetochores in anaphase, HeLa-Kyoto cells were seeded in glass-bottom 24-well plates (Cellvis \#P24-1.5H-N) and cotransfected with 
approximately 24 hours before imaging. Cells were treated with $2 \mu \mathrm{g} / \mathrm{mL}$ doxycycline to induce expression approximately 12-18 hours before imaging. Cells were imaged at 20 second time intervals. To more clearly visualize spindle poles and kinetochores, images of PCM-RFP and mCh-CENPB signal were background subtracted by duplicating each frame, applying a gaussian blur (sigma 30 pixels), and subtracting this blurred image from the original. For each frame, a line was drawn between spindle poles (PCM-RFP signal) to measure the distance between them, and the intensity of KIF22-GFP and mCh-CENPB along this line was plotted. These data sets were split at the center distance to generate two plots, and the distance between plot maxima and the distance from maxima to the spindle poles were calculated using MATLAB (scripts available at https://github.com/StumpffLab/lmage-Analysis).

\section{Assessment of cytokinesis failure}

To visualize cell boundaries, HeLa-Kyoto cells were transfected with mCh-CAAX using Lipofectamine LTX approximately 24-32 hours before imaging and treated with $2 \mu \mathrm{g} / \mathrm{mL}$ doxycycline approximately 8 hours before imaging. Cells were imaged at 3-minute intervals. Cells were scored as failing cytokinesis if the product of mitosis was a single cell with a single boundary of mCh-CAAX signal.

\section{Nuclear morphology quantification}

HeLa-Kyoto or RPE-1 cells were treated with $2 \mu \mathrm{g} / \mathrm{mL}$ doxycycline to induce expression approximately 24 hours before fixation. Nuclear solidity was measured for each interphase nucleus in each imaged field. The $5^{\text {th }}$ percentile of solidity for control cells (transfected with control siRNA and expressing GFP) was used as a threshold below which nuclear solidity was considered abnormal.

To assess the ability of nuclei to retain nuclear-localized proteins, cells were transfected with mCh-NLS using Lipofectamine LTX approximately 24-32 hours before imaging and treated with $2 \mu \mathrm{g} / \mathrm{mL}$ doxycycline approximately 8 hours before imaging. Cells were imaged at 3-minute intervals during and after division, and the presence of mCh-NLS signal in all nuclear structures (KIF22-GFP positive regions) was assessed.

\section{Assessment of spindle dependence of nuclear morphology defects}

To assess whether nuclear morphology defects caused by KIF22 depend on force generation within the mitotic spindle, cells were treated with $2 \mu \mathrm{g} / \mathrm{mL}$ doxycycline approximately 
1033

1034

1035

1036

1037

1038

1039

1040

1041

1042

1043

1044

1045

1046

1047

1048

1049

1050

1051

1052

1053

1054

1055

1056

\#SC301) approximately 1.5-2 hours before imaging, and $500 \mathrm{nM}$ nocodazole (Selleckchem \#S2775) and $900 \mathrm{nM}$ reversine (Cayman Chemical \#10004412) approximately 0.5-1 hour before imaging. Cells were imaged at 5-minute intervals. Nuclear solidity was measured 15 minutes before chromosome condensation and 100 minutes after chromosome decondensation.

\section{Proliferation assay}

HeLa-Kyoto cells were seeded in a 96-well plate and treated with $2 \mu \mathrm{g} / \mathrm{mL}$ doxycycline to induce expression or transfected with KIF22 siRNA approximately eight hours before the first assay timepoint. Automated bright field imaging using a Cytation 5 Cell Imaging Multi-Mode Reader (Biotek) (4X Plan Fluorite 0.13 NA objective (Olympus)) driven by Gen5 software (Biotek) was used to measure cell proliferation (Marquis et al. 2021). Images were collected every 4 hours for 96 hours. Gen5 software was used to process images and count the number of cells in each imaged field. Cell counts were normalized to the cell count in the first image acquired at time 0. Fold change at 96 hours was calculated by dividing the cell count at 96 hours by the cell count at time 0 . Predicted cell counts at 48 hours were calculated using an experimentally determined doubling time of 20.72 hours for the control case where all cells divide $\left(\operatorname{Cells}_{T}=2^{\left(\frac{T}{20.72}\right)}\right)$, the case where nuclear morphology defects limit proliferation and $60 \%$ of cells do not divide $\left(\right.$ Cells $_{T}=$

$\left.1.4^{\left(\frac{T}{20.72}\right)}\right)$, and the case where cytokinesis failure limits proliferation and $30 \%$ of cells do not divide $\left(\right.$ Cells $\left._{T}=1.7^{\left(\frac{T}{20.72}\right)}\right)$.

\section{Statistical analyses}

Statistical tests were performed using GraphPad Prism software (GraphPad Software, Inc.), version 9.2.0. Specific statistical tests and $n$ values for reported data are indicated in the figure legends. All data represent a minimum of three independent experiments. 
bioRxiv preprint doi: https://doi.org/10.1101/2021.09.29.462402; this version posted November 19, 2021. The copyright holder for this preprint (which was not certified by peer review) is the author/funder, who has granted bioRxiv a license to display the preprint in perpetuity. It is made available under aCC-BY 4.0 International license.

1057 Table 1

\begin{tabular}{|c|c|c|c|}
\hline Plasmid & Description & Primers (5' to 3', Fw: Forward, Rev: Reverse) & Source \\
\hline pEM784 & nICre recombinase & NA & $\begin{array}{l}\text { Khandelia } 2011 \\
\text { PMID } 21768390\end{array}$ \\
\hline pEM791 & $\begin{array}{l}\text { EGFP for } \\
\text { recombination }\end{array}$ & NA & $\begin{array}{l}\text { Khandelia } 2011 \\
\text { PMID } 21768390\end{array}$ \\
\hline pJS2161 & GFP-KIF22 & NA & $\begin{array}{l}\text { Stumpff } 2012 \\
\text { PMID } 22595673\end{array}$ \\
\hline pAT4206 & KIF22-GFP & $\begin{array}{l}\text { Fw: TACGTGGAATTCCACCATGGCCGCGGGCGGCTCGA } \\
\text { Rev: GTGACTGGTACCTGGAGGCGCCACAGCGCTGGC }\end{array}$ & This study \\
\hline pAT4226 & $\begin{array}{l}\text { KIF22-GFP, siRNA } \\
\text { resistant }\end{array}$ & $\begin{array}{l}\text { Fw: GGGCATGGACAGCTGCTCACTCGAAATCGCTAACTGGAGGA } \\
\text { ACCAC } \\
\text { Rev: GTGGTTCCTCCAGTTAGCGATTTCGAGTGAGCAGCTGTCCA } \\
\text { TGCCC }\end{array}$ & This study \\
\hline pAT4250 & $\begin{array}{l}\text { KIF22-GFP, siRNA } \\
\text { resistant, for } \\
\text { recombination }\end{array}$ & $\begin{array}{l}\text { Fragment Fw: } \\
\text { CTGGGCACCACCATGGCCGCG } \\
\text { Fragment Rev: } \\
\text { GCTAGCTCGATTACTTGTACAGCTCGTCCATGCC } \\
\text { Vector Fw: } \\
\text { GTACAAGTAATCGAGCTAGCATATGGATCCATATAACT } \\
\text { Vector Rev: } \\
\text { CATGGTGGTGCCCAGTGCCTCACGACC }\end{array}$ & This study \\
\hline pAT4251 & $\begin{array}{l}\text { KIF22-GFP R149Q, } \\
\text { siRNA resistant, for } \\
\text { recombination }\end{array}$ & $\begin{array}{l}\text { Fw: GGGGTGATCCCGCAGGCTCTCATGGAC } \\
\text { Rev: GTCCATGAGAGCCTGCGGGATCACCCC }\end{array}$ & This study \\
\hline pAT4258 & $\begin{array}{l}\text { KIF22-GFP V475G, } \\
\text { siRNA resistant, for } \\
\text { recombination }\end{array}$ & $\begin{array}{l}\text { Fw: TGCTAATGAAGACAGGAGAAGAGAAGGACCT } \\
\text { Rev: AGGTCCTTCTCTTCTCCTGTCTTCATTAGCA }\end{array}$ & This study \\
\hline pAT4260 & $\begin{array}{l}\text { KIF22-GFP T463D, } \\
\text { siRNA resistant, for } \\
\text { recombination }\end{array}$ & $\begin{array}{l}\text { Fw: CCCCTCTGTTGAGTGACCCAAAGCGAGAGC } \\
\text { Rev: GCTCTCGCTTTGGGTCACTCAACAGAGGGG }\end{array}$ & This study \\
\hline pAT4261 & $\begin{array}{l}\text { KIF22-GFP T463A, } \\
\text { siRNA resistant, for } \\
\text { recombination }\end{array}$ & $\begin{array}{l}\text { Fw: CCTCTGTTGAGTGCCCCAAAGCGAG } \\
\text { Rev: CTCGCTTTGGGGCACTCAACAGAGG }\end{array}$ & This study \\
\hline pAT4264 & $\begin{array}{l}\text { KIF22-GFP R149L, } \\
\text { siRNA resistant, for } \\
\text { recombination }\end{array}$ & $\begin{array}{l}\text { Fw: GGGTGATCCCGCTGGCTCTCATGGAC } \\
\text { Rev: GTCCATGAGAGCCAGCGGGATCACCC }\end{array}$ & This study \\
\hline pAT4269 & $\begin{array}{l}\text { KIF22-GFP P148L, } \\
\text { siRNA resistant, for } \\
\text { recombination }\end{array}$ & $\begin{array}{l}\text { Fw: CCTGGGGTGATCCTGCGGGCTCTCATG } \\
\text { Rev: CATGAGAGCCCGCAGGATCACCCCAGG }\end{array}$ & This study \\
\hline pAT4270 & $\begin{array}{l}\text { KIF22-GFP P148S, } \\
\text { siRNA resistant, for } \\
\text { recombination }\end{array}$ & $\begin{array}{l}\text { Fw: CTGGGGTGATCTCGCGGGCTCTCATG } \\
\text { Rev: CATGAGAGCCCGCGAGATCACCCCAG }\end{array}$ & This study \\
\hline
\end{tabular}




\section{ACKNOWLEDGEMENTS}

This work was supported by NIH F31AR074887 to AFT and NIH R01GM121491 to JKS. We thank the Mayo Clinic Center for Individualized Medicine (CIM) for supporting this research through the CIM Investigative and Functional Genomics program. We thank Alan Howe for the mCh-CAAX plasmid, and Ryoma Ohi for reagents and acceptor cells for recombination-mediated cassette exchange. We thank Rachel Stadler for technical assistance with data analysis and thank Laura Reinholdt and Matthew Warman for constructive discussions regarding this work. The authors declare no competing financial interests.

\section{VIDEO LEGENDS}

\section{Video 1. Fluorescence recovery after photobleaching of KIF22-GFP.}

Fluorescence recovery after photobleaching (FRAP) in HeLa-Kyoto cells expressing KIF22-GFP (top), KIF22-GFP R149Q (middle), or KIF22-GFP V475G (bottom). Cells represent interphase (left), metaphase (middle), or anaphase (right). Bleaching occurred at time zero. Scale bar $10 \mu \mathrm{m}$. Cells were imaged at 5 second intervals for 25 seconds before bleaching, photobleached, and imaged at 20 second intervals for 10 minutes after bleaching. Playback at 10 frames per second.

\section{Video 2. Anaphase in HeLa-Kyoto cells.}

Anaphase chromosome segregation in HeLa-Kyoto cells expressing KIF22-GFP (left), KIF22GFP R149Q (middle), or KIF22-GFP V475G (right). Magenta: SiR-Tubulin, green: KIF22-GFP. Times indicate minutes after anaphase onset. Scale bar $5 \mu \mathrm{m}$. Cells were imaged at 1 minute intervals. Playback at 10 frames per second (600X real time).

\section{Video 3. Anaphase in RPE-1 cells.}

Anaphase chromosome segregation in RPE-1 cells expressing KIF22-GFP (left), KIF22-GFP R149Q (middle), or KIF22-GFP V475G (right). Magenta: SiR-Tubulin, green: KIF22-GFP. Times indicate minutes after anaphase onset. Scale bar $5 \mu \mathrm{m}$. Cells were imaged at 1 minute intervals. Playback at 10 frames per second (600X real time).

\section{Video 4. Anaphase spindle pole separation.}

Anaphase in HeLa-Kyoto cells expressing pericentrin-RFP (magenta), CENPB-mCh (magenta), and KIF22-GFP (cyan). Times indicate seconds after anaphase onset. Scale bar $5 \mu \mathrm{m}$. Cells were imaged at 20 second intervals. Playback at 15 frames per second (300X real time). 
1092

1093

1094

1095

1096

1097

1098

1099

1100

1101

1102

1103

1104

1105

1106

1107

1108

1109

1110

1111

1112

1113

1114

1115

1116

1117

1118

1119

1120

1121

1122

1123

1124

1125
Video 5. Cytokinesis and cytokinesis failure.

Mitosis and cytokinesis in HeLa-Kyoto cells expressing KIF22-GFP (left), KIF22-GFP R149Q (middle), or KIF22-GFP V475G (right) (all KIF22-GFP represented in green) and mCh-CAAX (magenta). Scale bar $10 \mu \mathrm{m}$. Cells were imaged at 3 minute intervals. Playback at 25 frames per second (4500X real time).

\section{REFERENCES}

Adzhubei, I.A. et al., 2010. A method and server for predicting damaging missense mutations. Nature Methods, 7(4), pp.248-249.

Antonio, C. et al., 2000. Xkid, a chromokinesin required for chromosome alignment on the metaphase plate. Cell, 102(4), pp.425-435.

Asbury, C.L., 2017. Anaphase A: Disassembling Microtubules Move Chromosomes toward Spindle Poles. Biology, 6(1), p.15.

Asselin, L. et al., 2020. Mutations in the KIF21B kinesin gene cause neurodevelopmental disorders through imbalanced canonical motor activity. Nature communications, pp.1-18.

Bianchi, S. et al., 2016. Structural basis for misregulation of kinesin KIF21A autoinhibition by CFEOM1 disease mutations. Scientific Reports, 6(1), pp.30668-16.

Bieling, P., Kronja, I. and Surrey, T., 2010. Microtubule Motility on Reconstituted Meiotic Chromatin. Current Biology, 20(8), pp.763-769.

Blasius, T.L. et al., 2021. Sequences in the stalk domain regulate auto-inhibition and ciliary tip localization of the immotile kinesin-4 KIF7. Journal of cell science, 134(13).

Bodnar, A.G. et al., 1998. Extension of life-span by introduction of telomerase into normal human cells. Science (New York, N.Y.), 279(5349), pp.349-352.

Boyden, E.D. et al., 2011. Recurrent dominant mutations affecting two adjacent residues in the motor domain of the monomeric kinesin KIF22 result in skeletal dysplasia and joint laxity. American journal of human genetics, 89(6), pp.767-772.

Brouhard, G.J. and Hunt, A.J., 2005. Microtubule movements on the arms of mitotic chromosomes: polar ejection forces quantified in vitro. Proceedings of the National Academy of Sciences, 102(39), pp.13903-13908.

Brust-Mascher, I. et al., 2004. Model for anaphase B: role of three mitotic motors in a switch from poleward flux to spindle elongation. Proceedings of the National Academy of Sciences, 101(45), pp.15938-15943.

Cameron, L.A. et al., 2006. Kinesin 5-independent poleward flux of kinetochore microtubules in PtK1 cells. The Journal of Cell Biology, 173(2), pp.173-179. 
Cassimeris, L., Rieder, C.L. and Salmon, E.D., 1994. Microtubule Assembly and Kinetochore Directional Instability in Vertebrate Monopolar Spindles - Implications for the Mechanism of Chromosome Congression. Journal of cell science, 107, pp.285-297.

Cheng, L. et al., 2014. Human CFEOM1 Mutations Attenuate KIF21A Autoinhibition and Cause Oculomotor Axon Stalling. Neuron, 82(2), pp.334-349.

Cimini, D., Cameron, L.A. and Salmon, E.D., 2004. Anaphase spindle mechanics prevent missegregation of merotelically oriented chromosomes. Current Biology, 14(23), pp.2149_ 2155.

Civelekoglu-Scholey, G. et al., 2013. Dynamic bonds and polar ejection force distribution explain kinetochore oscillations in PtK1 cells. The Journal of Cell Biology, 201(4), pp.577593.

Cousin, M.A. et al., 2019. RINT1 Bi-allelic Variations Cause Infantile-Onset Recurrent Acute Liver Failure and Skeletal Abnormalities. American journal of human genetics, 105(1), pp.108-121.

Coy, D.L. et al., 1999. Kinesin's tail domain is an inhibitory regulator of the motor domain. Nature cell biology, 1(5), pp.288-292.

Dodds, G.S., 1930. Row formation and other types of arrangement of cartilage cells in endochondral ossification. The Anatomical Record, 46(4), pp.385-399.

Espeut, J. et al., 2008. Phosphorylation Relieves Autoinhibition of the Kinetochore Motor CenpE. Molecular cell, 29(5), pp.637-643.

Friedman, D.S. and Vale, R.D., 1999. Single-molecule analysis of kinesin motility reveals regulation by the cargo-binding tail domain. Nature cell biology, 1(5), pp.293-297.

Fu, C. et al., 2009. Phospho-Regulated Interaction between Kinesin-6 Klp9p and Microtubule Bundler Ase1p Promotes Spindle Elongation. Developmental Cell, 17(2), pp.257-267.

Funabiki, H. and Murray, A.W., 2000. The Xenopus chromokinesin Xkid is essential for metaphase chromosome alignment and must be degraded to allow anaphase chromosome movement. Cell, 102(4), pp.411-424.

Gan, H. et al., 2019. KIF5B modulates central spindle organization in late-stage cytokinesis in chondrocytes. Cell and Bioscience, pp.1-16.

Germani, A. et al., 2000. SIAH-1 interacts with alpha-tubulin and degrades the kinesin Kid by the proteasome pathway during mitosis. Oncogene, 19(52), pp.5997-6006.

Gillingham, A.K. and Munro, S., 2000. The PACT domain, a conserved centrosomal targeting motif in the coiled-coil proteins AKAP450 and pericentrin. EMBO reports, 1(6), pp.524-529.

Haila, S. et al., 2001. SLC26A2 (diastrophic dysplasia sulfate transporter) is expressed in developing and mature cartilage but also in other tissues and cell types. The journal of histochemistry and cytochemistry : official journal of the Histochemistry Society, 49(8), pp.973-982. 
1163

1164

1165

1166

1167

1168

1169

1170

1171

1172

1173

1174

1175

1176

1177

1178

1179

1180

1181

1182

1183

1184

1185

1186

1187

1188

1189

1190

1191

1192

1193

1194

1195

1196

1197

1198

1199

Hammond, J.W. et al., 2010. Autoinhibition of the kinesin-2 motor KIF17 via dual intramolecular mechanisms. The Journal of Cell Biology, 189(6), pp.1013-1025.

Hammond, J.W. et al., 2009. Mammalian Kinesin-3 Motors Are Dimeric In Vivo and Move by Processive Motility upon Release of Autoinhibition M. Schliwa, ed. PLOS Biology, 7(3), pp.e1000072-14.

Hatch, E.M. et al., 2013. Catastrophic Nuclear Envelope Collapse in Cancer Cell Micronuclei. Cell, 154(1), pp.47-60.

Hershko, A., 1999. Mechanisms and regulation of the degradation of cyclin B. Philosophical transactions of the Royal Society of London. Series B, Biological sciences, 354(1389), pp.1571-5- discussion 1575-6.

lemura, K. and Tanaka, K., 2015. Chromokinesin Kid and kinetochore kinesin CENP-E differentially support chromosome congression without end-on attachment to microtubules. Nature communications, 6, pp.1-11.

Imanishi, M. et al., 2006. Autoinhibition regulates the motility of the C. elegans intraflagellar transport motor OSM-3. The Journal of Cell Biology, 174(7), pp.931-937.

Ioannidis, N.M. et al., 2016. REVEL: An Ensemble Method for Predicting the Pathogenicity of Rare Missense Variants. The American Journal of Human Genetics, 99(4), pp.877-885.

Khandelia, P., Yap, K. and Makeyev, E.V., 2011. Streamlined platform for short hairpin RNA interference and transgenesis in cultured mammalian cells. Proceedings of the National Academy of Sciences of the United States of America, 108(31), pp.12799-12804.

Lefeber, D.J., Morava, E. and Jaeken, J., 2011. How to find and diagnose a CDG due to defective N-glycosylation. Journal of inherited metabolic disease, 34(4), pp.849-852.

Levesque, A.A. and Compton, D.A., 2001. The chromokinesin Kid is necessary for chromosome arm orientation and oscillation, but not congression, on mitotic spindles. The Journal of Cell Biology, 154(6), pp.1135-1146.

Levesque, A.A. et al., 2003. A functional relationship between NuMA and kid is involved in both spindle organization and chromosome alignment in vertebrate cells. Molecular biology of the cell, 14(9), pp.3541-3552.

Liu, D. et al., 2010. Regulated targeting of protein phosphatase 1 to the outer kinetochore by KNL1 opposes Aurora B kinase. The Journal of Cell Biology, 188(6), pp.809-820.

Liu, Y. et al., 2018. Genomic, Proteomic and Phenotypic Heterogeneity in HeLa Cells across Laboratories: Implications for Reproducibility of Research Results. bioRxiv, p.307421.

Marquis, C. et al., 2021. Chromosomally unstable tumor cells specifically require KIF18A for proliferation. Nature communications, pp.1-14.

Marshall, W.F. et al., 2001. Chromosome elasticity and mitotic polar ejection force measured in living Drosophila embryos by four-dimensional microscopy-based motion analysis. Current Biology, 11(8), pp.569-578. 
1200

1201

1202

1203

1204

1205

1206

1207

1208

1209

1210

1211

1212

1213

1214

1215

1216

1217

1218

1219

1220

1221

1222

1223

1224

1225

1226

1227

1228

1229

1230

1231

1232

1233

1234

1235

Min, B.-J. et al., 2011. Whole-exome sequencing identifies mutations of KIF22 in spondyloepimetaphyseal dysplasia with joint laxity, leptodactylic type. American journal of human genetics, 89(6), pp.760-766.

Morgan, D.O., 1995. Principles of CDK regulation. Nature, 374(6518), pp.131-134.

Nislow, C. et al., 1992. A plus-end-directed motor enzyme that moves antiparallel microtubules in vitro localizes to the interzone of mitotic spindles. Nature, 359(6395), pp.543-547.

Ohsugi, M. et al., 2003. Cdc2-mediated phosphorylation of Kid controls its distribution to spindle and chromosomes. The EMBO journal, 22(9), pp.2091-2103.

Ohsugi, M. et al., 2008. Kid-Mediated Chromosome Compaction Ensures Proper Nuclear Envelope Formation. Cell, 132(5), pp.771-782.

Quang, D., Chen, Y. and Xie, X., 2015. DANN: a deep learning approach for annotating the pathogenicity of genetic variants. Bioinformatics (Oxford, England), 31(5), pp.761-763.

Ren, J. et al., 2018. Coiled-coil 1-mediated fastening of the neck and motor domains for kinesin3 autoinhibition. Proceedings of the National Academy of Sciences of the United States of America, 115(51), pp.E11933-E11942.

Rentzsch, P. et al., 2018. CADD: predicting the deleteriousness of variants throughout the human genome. pp.1-9.

Rieder, C.L. and Salmon, E.D., 1994. Motile kinetochores and polar ejection forces dictate chromosome position on the vertebrate mitotic spindle. The Journal of Cell Biology, 124(3), pp.223-233.

Rieder, C.L. et al., 1986. Oscillatory movements of monooriented chromosomes and their position relative to the spindle pole result from the ejection properties of the aster and halfspindle. The Journal of Cell Biology, 103(2), pp.581-591.

Ris, H., 1949. The anaphase movement of chromosomes in the spermatocytes of the grasshopper. The Biological bulletin, 96(1), pp.90-106.

Rossi, A. and Superti-Furga, A., 2001. Mutations in the diastrophic dysplasia sulfate transporter (DTDST) gene (SLC26A2): 22 novel mutations, mutation review, associated skeletal phenotypes, and diagnostic relevance. Human Mutation, 17(3), pp.159-171.

Samwer, M. et al., 2017. DNA Cross-Bridging Shapes a Single Nucleus from a Set of Mitotic Chromosomes. Cell, 170(5), pp.956-972.e23.

Sawin, K.E. et al., 1992. Mitotic spindle organization by a plus-end-directed microtubule motor. Nature, 359(6395), pp.540-543.

Schindelin, J. et al., 2012. Fiji: an open-source platform for biological-image analysis. Nature Methods, 9(7), pp.676-682.

Schneider, C.A., Rasband, W.S. and Eliceiri, K.W., 2012. NIH Image to ImageJ: 25 years of image analysis. Nature Methods, pp.1-5. 
1236

1237

1238

1239

1240

1241

1242

1243

1244

1245

1246

1247

1248

1249

1250

1251

1252

1253

1254

1255

1256

1257

1258

1259

1260

1261

1262

1263

1264

1265

1266

1267

1268

1269

1270

1271

Schwarz, J.M. et al., 2010. MutationTaster evaluates disease-causing potential of sequence alterations. Nature Publishing Group, pp.1-2.

Serra-Marques, A. et al., 2020. The mitotic protein NuMA plays a spindle-independent role in nuclear formation and mechanics. The Journal of Cell Biology, 219(12), pp.348-23.

Shiroguchi, K. et al., 2003. The Second Microtubule-binding Site of Monomeric Kid Enhances the Microtubule Affinity. The Journal of biological chemistry, 278(25), pp.22460-22465.

Soeda, S., Yamada-Nomoto, K. and Ohsugi, M., 2016. The microtubule-binding and coiled-coil domains of Kid are required to turn off the polar ejection force at anaphase. Journal of cell science, 129(19), pp.3609-3619.

Straight, A.F., Sedat, J.W. and Murray, A.W., 1998. Time-lapse microscopy reveals unique roles for kinesins during anaphase in budding yeast. The Journal of Cell Biology, 143(3), pp.687694.

Stumpff, J. et al., 2012. Kif18A and Chromokinesins Confine Centromere Movements via Microtubule Growth Suppression and Spatial Control of Kinetochore Tension. Developmental Cell, 22(5), pp.1017-1029.

Stumpff, J. et al., 2008. The Kinesin-8 Motor Kif18A Suppresses Kinetochore Movements to Control Mitotic Chromosome Alignment. Developmental Cell, 14(2), pp.252-262.

Sturgill, E.G. et al., 2016. Kinesin-5 inhibitor resistance is driven by kinesin-12. The Journal of Cell Biology, 213(2), pp.213-227.

Su, K.-C. et al., 2016. A Regulatory Switch Alters Chromosome Motions at the Metaphase-toAnaphase Transition. Cell reports, 17(7), pp.1728-1738.

Takagi, J. et al., 2013. Chromosome position at the spindle equator is regulated by chromokinesin and a bipolar microtubule array. Scientific Reports, 3, pp.746-7.

Tanenbaum, M.E. et al., 2009. Kif15 Cooperates with Eg5 to Promote Bipolar Spindle Assembly. Current Biology, 19(20), pp.1703-1711.

Tokai, N. et al., 1996. Kid, a novel kinesin-like DNA binding protein, is localized to chromosomes and the mitotic spindle. The EMBO journal, 15(3), pp.457-467.

Tokai-Nishizumi, N. et al., 2005. The chromokinesin kid is required for maintenance of proper metaphase spindle size. Molecular biology of the cell, 16(11), pp.5455-5463.

Tüysüz, B. et al., 2014. Spondyloepimetaphyseal dysplasia with joint laxity, leptodactylic type: longitudinal observation of radiographic findings in a child heterozygous for a KIF22 mutation. Pediatric Radiology, 45(5), pp.771-776.

Uhlen, M. et al., 2015. Tissue-based map of the human proteome. Science (New York, N.Y.), 347(6220), pp.1260419-1260419.

van der Vaart, B. et al., 2013. CFEOM1-Associated Kinesin KIF21A Is a Cortical Microtubule Growth Inhibitor. Developmental Cell, 27(2), pp.145-160. 
1272

1273

1274

1275

1276

1277

1278

1279

1280

1281

1282

1283

1284

1285

1286

1288

1289

1290

1291

1292

1293

van Heesbeen, R.G.H.P., Tanenbaum, M.E. and Medema, R.H., 2014. Balanced Activity of Three Mitotic Motors Is Required for Bipolar Spindle Assembly and Chromosome Segregation. Cell reports, 8(4), pp.948-956.

Vaser, R. et al., 2015. SIFT missense predictions for genomes. Nature Protocols, 11(1), pp.1-9.

Verhey, K.J. and Hammond, J.W., 2009. Cytoskeletal motors: Traffic control: regulation of kinesin motors. pp.1-13.

Verhey, K.J. et al., 1998. Light chain-dependent regulation of Kinesin's interaction with microtubules. The Journal of Cell Biology, 143(4), pp.1053-1066.

Vukušić, K. et al., 2021. Microtubule-sliding modules based on kinesins EG5 and PRC1dependent KIF4A drive human spindle elongation. Developmental Cell, pp.1-42.

Vukušić, K., Buđa, R. and Tolić, I.M., 2019. Force-generating mechanisms of anaphase in human cells. Journal of cell science, 132(18), pp.jcs231985-11.

Wandke, C. et al., 2012. Human chromokinesins promote chromosome congression and spindle microtubule dynamics during mitosis. The Journal of Cell Biology, 198(5), pp.847-863.

Wolf, F. et al., 2006. Dose-dependent effects of stable cyclin B1 on progression through mitosis in human cells. The EMBO journal, 25(12), pp.2802-2813.

Yajima, J. et al., 2003. The human chromokinesin Kid is a plus end-directed microtubule-based motor. The EMBO journal, 22(5), pp.1067-1074.

Yount, A.L., Zong, H. and Walczak, C.E., 2015. Regulatory mechanisms that control mitotic kinesins. Experimental Cell Research, 334(1), pp.70-77.

Zhang, P. et al., 1990. A kinesin-like protein required for distributive chromosome segregation in Drosophila. Cell, 62(6), pp.1053-1062. 